\title{
Los insectos comestibles del Perú: Biodiversidad y perspectivas de la entomofagia en el contexto peruano
}

\author{
Edible insects of Peru: Biodiversity and perspectives on entomophagy in the Peruvian \\ context \\ 1,a Julio Rivera \\ ${ }^{2}$ Fabricio Carbonell
}

\begin{abstract}
ARTÍCULO DE REVISIÓN
${ }^{1}$ Universidad San Ignacio de Loyola. Grupo de Investigación en Entomología y Medio Ambiente. Lima, Perú.

E-mail: jrivera@usil.edu.pe Twitter:@piskomantis ${ }^{2}$ Ministerio de Ambiente y Energía. Sistema Nacional de Áreas de Conservación. Costa Rica.
\end{abstract}

aRCID: 0000-0001-8497-3042

Palabras clave: Biodiversidad, entomofagia, insecta, Perú.

Keywords: Biodiversity, entomophagy, insecta, Peru.

Información adicional

Presentado: $11 / 11 / 2020$

Aprobado: 27/12/2020
RESUMEN
La entomofagia, el consumo de insectos y sus derivados con fines nutricionales y/o terapéuticos, es una práctica cultural difundida en diversas regiones del mundo. El crecimiento poblacional y el impacto que el calentamiento global tendrán en la productividad agropecuaria convencional hacen necesario identificar fuentes complementarias de alimento sostenible. Por su alto contenido de proteínas, ácidos grasos, minerales y otros nutrientes, se estima que los insectos jugarán un rol importante en la seguridad alimentaria humana ante dicho escenario. Perú tiene una larga tradición de consumo de insectos; sin embargo, existe escasa documentación sobre las especies utilizadas, su distribución, forma de consumo y perfil nutricional. La presente revisión busca elaborar el primer listado nacional de insectos comestibles del Perú . Se halló que existen 66 especies reportadas de uso directo e indirecto, y otras 120 también presentes que, aunque su consumo no ha sido reportado en el Perú, este está documentado en países vecinos. En total se reportan 186 especies de facto o potencialmente utilizables: Hymenoptera (4 familias, 89 especies), Coleoptera (10 familias, 46 especies) y Lepidoptera (9 familias, 26 especies) representan el $86 \%$ de esta diversidad, mientras que Ephemeroptera, Odonata, Orthoptera, Blattodea, Hemiptera, Diptera, y Megaloptera, todos con 5 ó menos especies utilizadas, completan la lista. En base a estos hallazgos se discuten el potencial nutricional de los insectos, propuestas para fomentar el impulso de dicha industria en el Perú, y el valor de esta como estrategia adaptativa ante la transformación climática proyectada para el presente siglo.

ABSTRACT
Entomophagy, the consumption of insects and their derivatives for nutritional and/or therapeutic purposes, is a widespread cultural practice in various regions of the world. Population growth and the impact that global warming is expected to have on conventional agricultural productivity, make it necessary to identify complementary sources of sustainable food. Due to their high content of proteins, fatty acids, minerals and other nutrients, it is estimated that insects will play an important role in human food security under this scenario. Peru has a long tradition of consuming insects; however, there is little documentation on the species used, their distribution, form of consumption and nutritional profile. This review seeks to elaborate on the first national list of edible insects of Peru. It was found that there are $66 \mathrm{spp}$. reported that are subject of direct or indirect use, and another $120 \mathrm{spp}$. also present whose consumption has not been reported in Peru yet they are consumed in neighboring countries. In total 186 de facto or potentially usable species are reported: Hymenoptera (4 families, 89 species), Coleoptera (10 families, 46 species) and Lepidoptera (9 families, 26 species), represent $86 \%$ of this diversity, while Ephemeroptera, Odonata, Orthoptera, Blattodea, Hemiptera, Diptera, and Megaloptera, all with 5 or fewer species used, complete the list. Based on these findings, the nutritional potential of insects, proposals to promote this industry in Peru, and the value of it as an adaptive strategy in the face of the climate transformation projected for this century, are discussed. 


\section{INTRODUCCIÓN}

La clase Insecta es uno de los linajes de animales más exitosos, diversos y abundantes del planeta, con un registro fósil que se remonta al menos a 400 millones de años en el Devónico (Grimaldi \& Engel, 2005). Aunque se desconoce el número real de especies de insectos, diversas estimaciones sitúan las cifras entre 2 y 50 millones (Stork, 1993). Cálculos recientes basados en datos puntuales sugieren una diversidad global de 5.5 millones de especies, de los cuales 1.5 millones son escarabajos (Coleoptera) (Stork et al., 2015; Stork, 2018). Su abundancia y diversidad hacen de los insectos componentes omnipresentes de los ecosistemas terrestres y una poderosa fuerza ecológica y evolutiva en todo el planeta (Scudder, 2009).

La versatilidad evolutiva de los insectos se refleja en la amplia gama de nichos que ocupan; sus roles tróficos como herbívoros, depredadores, detritívoros y parasitoides hacen que estos sean de suma relevancia en el manejo de agroecosistemas (Jankielsohn, 2018). Los insectos también facilitan en gran medida la reproducción de las plantas a través de su función como polinizadores, permitiendo la producción de frutos y semillas, ambos recursos valiosos en sistemas tróficos y para la seguridad alimentaria de nuestra especie (Ollerton et al., 2011). Los insectos son también importantes para la medicina humana y veterinaria, ya que muchos actúan como vectores de patógenos causantes de enfermedades, tales como la malaria, dengue, mal de Chagas, leishmaniasis, entre otras (Rodhain, 2015). Numerosas especies y sus productos únicos (e.g., miel, jalea real, cera, seda, propóleo, tinte de cochinilla, goma laca, tinta de hiel de hierro y varios otros productos derivados utilizados en medicina tradicional) también constituyen fuentes importantes de ingresos y valor cultural para muchas comunidades alrededor del mundo (Blas \& del Hoyo, 2013). Los insectos también se utilizan cada vez más como modelos de inspiración en diversas disciplinas tecnocientíficas humanas (ingeniería, genética, nanotecnología, biomimética) (Leather, 2015). En general, los insectos desempeñan una miríada de servicios ecosistémicos y culturales irremplazables, lo que los convierte en organismos de gran importancia para el funcionamiento de los ecosistemas y la cultura humana (Hogue, 1987; Scudder, 2009).

Los insectos han jugado históricamente otro papel importante para los humanos: el de alimento. La práctica de consumir insectos, también conocida como entomofagia, es una tradición transcultural milenaria que aún persiste en muchas sociedades alrededor del mundo (McGrew, 2001; Raubenheimer \& Rothman, 2013). Los insectos forman parte de la dieta de personas de todos los continentes por buenas razones: son nutricionalmente densos, hiperdiversos y relativamente abundantes. Aproximadamente 2000 especies de insectos son consumidas por humanos de aproximadamente 3000 grupos étnicos en todo el mundo (Ramos - Elorduy, 2009); al menos 113 países, particularmente de Asia, África y América, muestran alguna forma de utilización (Gahukar, 2011; Hazarika et al., 2020). La forma tradicional de consumo es a través de la cosecha directa en el hábitat natural o en agroecosistemas (Payne \& Van Itterbeeck, 2017), aunque en tiempos recientes la crianza de insectos a diferentes escalas y en granjas especialmente acondicionadas para tal fin, producidos tanto para consumo humano como animal, viene convirtiéndose en una práctica extendida y rentable en diversas regiones del mundo (Madau et al., 2020).

La entomofagia existe en el Perú, aunque históricamente ha sido muy poco estudiada y, por ende, documentada. Por ejemplo, mientras que el consumo de insectos ha sido intermitentemente documentado en la Amazonía peruana (e.g., Casas Reátegui et al., 2018), es muy poco lo que se sabe de esta práctica en la región Andina, esto a pesar de que varias especies de insectos se consumen de manera regular en aquella región (e. g. Jara \& Franco, 1985; Grados et al., 2015). En el caso de la costa, la entomofagia parece haber sido una práctica poco relevate, quizá debido a que la biodiversidad marina 
ha jugado un rol más importante en la alimentación de los pobladores de esta región, de otro modo caracterizada por su aridez y escasa biodiversidad terrestre. En términos generales, la producción científica sobre la entomofagia en el Perú ha sido muy limitada, y como resultado contamos con poca información sobre la diversidad taxonómica y distribución geográfica de las especies que se usan como alimento en el Perú, así como también su forma de consumo y potencial de uso.

El Perú es prolijo en casos de biodiversidad subutilizada. Por ejemplo, la cañihua, la kiwicha, la cocona, el tarwi y la sacha papa son ejemplos emblemáticos de especies de gran valor nutricional que, aunque populares en el pasado, su uso actual se restringe mayormente a sus productores y consumidores locales (Pastor et al., 2006). Los insectos claramente siguen este patrón de subutilización, a pesar de los beneficios nutricionales y culturales asociados a su consumo. Debido a que el ámbito de la entomofagia es inherentemente vasto, en virtud de las múltiples dimensiones que esta involucra, la presente es una revisión en forma de una descripción general y narrativa de la literatura, que se enfoca en aspectos que consideramos relevantes para el contexto peruano, integrando conocimientos adquiridos a partir de nuestras investigaciones, experiencias de campo, interacción con comunidades nativas, y retroalimentación de colegas y colaboradores de disciplinas afines. El resultado es un documento que no solo busca ser un reporte faunístico de especies (de facto y potencialmente) comestibles, sino también una referencia esencial que busca informar esfuerzos futuros orientados a estudios más sistemáticos e integrativos sobre la entomofagia en el Perú.

\section{Antecedentes sobre el estudio de la entomofagia en el Perú}

Las crónicas del antiguo Perú y las representaciones pictóricas en textiles y cerámicos muestran que los insectos fueron componentes relevantes de la cultura de los antiguos peruanos (Lamas, 1980; Fernández Baca, 1980; Vargas-Musquipa, 1995; Suclli et al., 2019). La evidencia más antigua del consumo de insectos en el Perú proviene de coprolitos de por lo menos 4220 años de antigüedad, durante el precerámico de la costa central (Weir \& Bonavia, 1985; Bonavia et al., 1993). Aunque existe documentación anecdótica en las crónicas prehispánicas y coloniales sobre el consumo de insectos en el antiguo Perú (Bodenheimer, 1951; Grados et al., 2015), el estudio moderno de esta práctica en el país tiene sus raíces en la literatura antropológica del siglo XX. A través de la recopilación de observaciones históricas hechas por cronistas, viajeros, misioneros, y la observación participativa como método principal de documentación, los primeros reportes modernos sobre el uso de insectos como alimento provienen de estudios etnográficos conducidos por antropólogos extranjeros en pueblos originarios de la Amazonía peruana, tales como los Cocama, Asháninca y Yagua (Métraux, 1963; Steward \& Métraux, 1963; Denevan 1971). Aunque dichos estudios brindan una visión general de diversas prácticas culturales y su contexto ecológico y cosmológico, el tratamiento de los insectos no suele ser exhaustivo en cuanto a la documentación taxonómica de las especies utilizadas por estas etnias. Por ejemplo, en dichos tratados los autores mencionan "hormigas" o "gusanos" como parte de la dieta de estos pueblos; sin embargo, estos nombres son etiquetas genéricas que pueden referir a innumerables especies y por ende no capturan el espectro de biodiversidad de especies de insectos consumidos. A pesar de esta falencia, dichos estudios dejan entrever ciertas prácticas asociadas al consumo de insectos, por ejemplo, formas de forrajeo diferenciadas en base al sexo y edad de los miembros de una comunidad o estilos de preparación. Aparte de las contribuciones aisladas sobre los insectos comestibles del Perú hechas por investigadores extranjeros, destacan los estudios de Escomel $(1919,1926)$ y Escomel \& Maldonado (1921) sobre el uso en medicina tradicional Andina de ciertos escarabajos del género Pseudomeloe (Meloidae) conocidos como uchu curo. Una contribución importante fue publicada por Paoletti et al. (2000), en donde los autores realizan una síntesis del conocimiento actual sobre la entomofagia en la amazonia. En general, el interés por el tema de la entomofagia en el Perú fue virtualmente nulo durante el sigloXX y esto se ve reflejado en la ausencia de publicaciones científicas al respecto producidas localmente durante este periodo. 
A partir del inicio del siglo XXI, la producción científica local muestra un subito incremento, apareciendo nuevos estudios documentando la entomofagia en el Perú desde enfoques diversos. Destacan aquellos con una orientación nutricional que argumentan sobre la importancia de rescatar y promover prácticas tradicionales (entre ellas, la entomofagia) para dar forma a políticas públicas que garanticen la seguridad alimentaria de comunidades nativas de la Amazonia peruana (Roche et al., 2007, 2008, 2011; Creed-Kanashiro et al., 2009). Complementario al ámbito nutricional se encuentran aportes recientes sobre la composición química de algunas especies de consumo difundido o con potencial para industrialización y consumo masivo (Valdez-Pantoja \& Untiveros-Bermúdez, 2010; Vargas et al., 2013; Apolo-Arévalo \& Iannacone, 2015; Romero \& Catacora, 2017). La meliponicultura, el manejo de abejas nativas sin aguijón o meliponas para la producción de miel, también ha ganado notoriedad en tiempos recientes y en diversos ámbitos, tales como faunística, prácticas tradicionales de manejo y usos, así como también caracterización bioquímica de mieles producidas por estas abejas (Rasmussen \& Castillo, 2003; Elizalde et al., 2007; Rasmussen \& González, 2009; Rodríguez-Malaver et al., 2009; Erizalde \& Castillo-Carrillo, 2010; Perichon, 2013; Rasmussen \& Delgado, 2019). A pesar de la diversificación de los ámbitos de estudio, el enfoque etnológico continúa proveyendo del marco conceptual sobre el cual la mayoría de los estudios locales de entomofagia en el Perú se apoyan y justifican (e.g. Perichon, 2013; Romero \& Catacora, 2017; Casas Reátegui et al., 2018; Manno et al., 2018). La documentación taxonómica de las especies comestibles también se torna más rigurosa a partir del siglo XXI, al denotarse mayores esfuerzos por parte de los autores en brindar identificaciones taxonómicas más precisas de las especies citadas, algo que sin duda ayuda a incrementar el valor científico de dichas contribuciones. Sin embargo, también se evidencia algunas limitaciones para la identificación a nivel genérico y, especialmente, a nivel de especie.

\section{¿Cuáles son los insectos comestibles del Perú?}

Para elaborar el listado de especies comestibles del Perú utilizamos dos alcances. Primero, se condujo una revisión de literatura especializada producida durante el siglo XX y XXI para así identificar aquellas especies que han sido oficialmente reportadas para el país (Tabla 1). Sin embargo, la entomofagia ha recibido poca atención por parte de la comunidad científica local, lo cual hace suponer que, siendo un país megadiverso, el Perú alberga una biodiversidad importante de insectos comestibles cuya condición como tal ha eludido documentación formal. Para compensar esta evidente brecha de información, condujimos una segunda revisión de literatura tomando como punto de partida el listado global de especies de insectos comestibles de Jongema (2017), el cual contrastamos con varios catálogos, listas de especies y tratados taxonómicos de insectos para determinar cuáles de estas especies se encuentran también en Perú. Esta segunda lista se presenta en la Tabla 2. Para complementar la lista de insectos comestibles del Perú con datos de distribución geográfica a nivel departamental, se examinó la colección de insectos del Museo de Entomología Klaus Raven Büller, Universidad Nacional Agraria la Molina, en Lima, así como también información recopilada mayormente por F.C. durante múltiples excursiones y visitas a comunidades originarias de la Amazonia: Shipibos (Pucallpa), Yaguas (Iquitos), Aguarunas (Amazonas), Piros y Matsigenkas (Madre de Dios).

La literatura registra al menos 66 especies de insectos sujetas a alguna forma de consumo o utilización en el Perú, para un total de 20 familias en ocho órdenes (Tabla 1). La gran mayoría de las especies reportadas (63 spp.) corresponden a insectos holometábolos, es decir, aquellos que muestran metamorfosis completa (huevo, larva, pupa e insecto adulto): Hymenoptera (abejas, avispas y hormigas), Coleoptera (escarabajos), Lepidoptera (mariposas y polillas), Megaloptera (megalópteros) y Diptera (moscas y mosquitos). Los insectos no holometábolos constituyen apenas 3 especies en las ordenes Ephemeroptera (efímeras), Orthoptera (grillos y saltamontes) y Hemiptera (chinches, pulgones, y queresas). La mayoría de las identificaciones taxonómicas asociadas a estos reportes (88 \%) 
son a nivel de especie, mientras que el resto son a nivel genérico. En este último caso, dos o más especies podrían estar siendo citadas bajo una única etiqueta genérica, sobre todo en grupos diversos como lo son los escarabajos Phyllophaga spp. (Scarabaeidae) (Romero \& Catacora, 2017) o las avispas Mischocyttarus spp. (Vespidae) (Casas Reategui et al., 2018).

Hymenoptera destaca entre los holometábolos por ser la orden con mayor número de especies utilizadas (34 spp.). La literatura reporta el consumo de larvas, pupas y adultos de diversos grupos de avispas y hormigas, destacando entre estas últimas Atta cephalotes (L.) y A. sexdens (L.), conocidas en la amazonia como "siquisapa". Otro aspecto relacionado al uso de himenópteros y que destaca en la literatura son los estudios sobre las abejas nativas de la tribu Meliponini, conocidas como abejas meliponas o "sin aguijón". La literatura cita al menos 21 especies de Meliponini sujetas a algún grado de explotación en estado silvestre, o de manera artesanal, en diversas regiones del Perú (Rasmussen, 2003; Rasmussen \& Castillo, 2003; Erizalde \& Castillo-Carrillo, 2010; Erizalde et al., 2007). Las abejas sin aguijón han recibido considerable atención en la última década debido a su potencial para el desarrollo de la industria de la meliponicultura y enfocada en la producción de miel, polen y otros derivados, una práctica ancestral que se mantiene vigente en varias partes del continente americano, incluyendo el Perú - aunque de manera aún incipiente. Otros himenópteros consumidos incluyen varias especies de avispas papeleras (Vespidae: Polistinae) en los géneros Polybia, Agelaia, Brachygastra y Mischocyttarus, todas especies cuyos nidos frecuentemente albergan numerosas larvas y pupas, los estadios preferidos para consumo. Rojas Zolezzi (2003) también menciona una especie de avispa alfarera del género Sceliphron (Sphecidae) que es consumida por comunidades Ashaninkas del río Ene. Estas avispas construyen nidos de barro para sus larvas usualmente de manera agregada.

Los coleópteros son los siguientes insectos en término de especies utilizadas ( $21 \mathrm{spp}$.). Aunque los escarabajos son utilizados principalmente como alimento en Perú, algunas especies también se usan con fines medicinales o terapéuticos. El consumo de coleópteros usualmente se extiende a especies con larvas relativamente grandes y fáciles de encontrar, o que suelen ocurrir de forma agregada, por ejemplo, barrenando tallos de árboles (e.g. Cerambycidae, Curculionidae), materia orgánica (e.g. Scarabaeidae), o en infrutescencias o tubérculos (Chrysomelidae, Curculionidae). La larva del gorgojo de la palma, Rhynchophorus palmarum (Curculionidae), conocida como "suri", emerge de la literatura como una de las especies de mayor relevancia en la Amazonía (Cartay et al., 2020), tanto por su consumo difundido como por su valor como suplemento nutricional, destacándose no solo su perfil químico, sino también aspectos ecológicos, socioeconómicos y culturales vinculados al uso de este recurso (Pérez \& Iannacone, 2006; Delgado et al., 2008; Sancho, 2012; Vargas et al., 2013; Correa Tang \& Delgado, 2016; Aguilera et al., 2017; Cartay, 2018; Delgado et al., 2019). Las voluminosas larvas de R. palmarum se extraen de los troncos de varios tipos de palmeras, especialmente Mauritiaflexuosa L.f. o "aguaje" (Delgado et al., 2008) y su consumo es difundido, incluso dentro del ámbito urbano. Otra especie de consumo habitual es Pachymerus nucleorum, conocida como "suri de la shapaja" o "curo", en la familia Chrysomelidae (Bruchinae). Las larvas de esta especie se desarrollan en los frutos de Attalea phalerata Mart. ex Spreng. y ha sido recientemente sujeta a exploración gastronómica (Ocampo et al., 2019). Otra especie relacionada y que ocurre en situaciones similares es Speciomerus giganteus, también consumido en la Amazonía (Correa Tang \& Delgado, 2016). La región Andina no es ajena al consumo de escarabajos. Manno et al. (2018) documentaron el consumo de larvas de Premnotrypes spp., que incluye varias especies conocidas colectivamente como "gorgojo de la papa", una plaga de suma importancia en los agroecosistemas andinos. Dentro de las especies andinas cabe también destacar a Austrelmis condimentarius (Philippi), un escarabajo acuático en la familia Elmidae. Con once especies en el Perú, el género Austrelmis es un componente distintivo de la comunidad bentónica de las quebradas altoandinas por encima de los $3000 \mathrm{~m}$ (Huanachin \& Huamantinco, 2018). El epíteto específico "condimentarius" hace alusión a su uso como alimento; según el mismo Philippi (1864), esta 
y otras especies de insectos acuáticos se utilizan en la preparación de un plato tradicional andino conocido como "chupe de chichi". Otras especies terrestres consumidas principalmente en su forma larval incluyen: Metamasius hemipterus Olivier y Rhinostomus barbirostris (F.) (Curculionidae); Callipogon sp., Macrodontia cervicornis (L.), Acanthoderes sp. y Acrocinus longimanus (L.) (Cerambycidae); Megaceras crassum Prell, Strategus jugurtha Burmeister, Dynastes hercules (L.), Megasoma sp., Phyllophaga spp., y Platycoelia lutescens Blanchard (Scarabaeidae). Escomel (1919, 1926) y Escomel \& Maldonado (1921) documentaron el uso de tres especies de Meloidae del género Pseudomeloe; las propiedades vesicantes de sus secreciones defensivas (cantaridina) se utilizan en medicina tradicional Andina para eliminar las verrugas cutáneas (Safenraiter et al., 2019). Finalmente, se tiene conocimiento de la introducción al Perú del escarabajo Tenebrio molitor (L.), especie sujeta a comercialización como alimento vivo en el mercado local de mascotas exóticas (reptiles, tarántulas, etc.), pero también utilizado como complemento fortificante en alimentos procesados para consumo humano y en la exploración gastronómica (Ocampo et al., 2019). Este escarabajo, miembro de la familia Tenebrionidae, es una especie cosmopolita por ser de gran importancia en la industria global de insectos comestibles. Otra especie introducida en el Perú es Ulomoides dermestoides Fairmaire, el llamado "gorgojo chino". Aunque no es un gorgojo (Curculionidae), sino más bien miembro de la familia Tenebrionidae, este escarabajo es consumido por algunas personas para combatir diversas afecciones respiratorias, musculares y hasta el cáncer. Aunque estudios científicos han encontrado algunas propiedades antiinflamatorias en extractos diluidos de este escarabajo (Santos et al., 2010), la evidencia sugiere por el contrario que su consumo excesivo puede conllevar a efectos adversos en el organismo (Crespo et al., 2011; Bhupinder et al., 2014; Natt et al., 2014). 

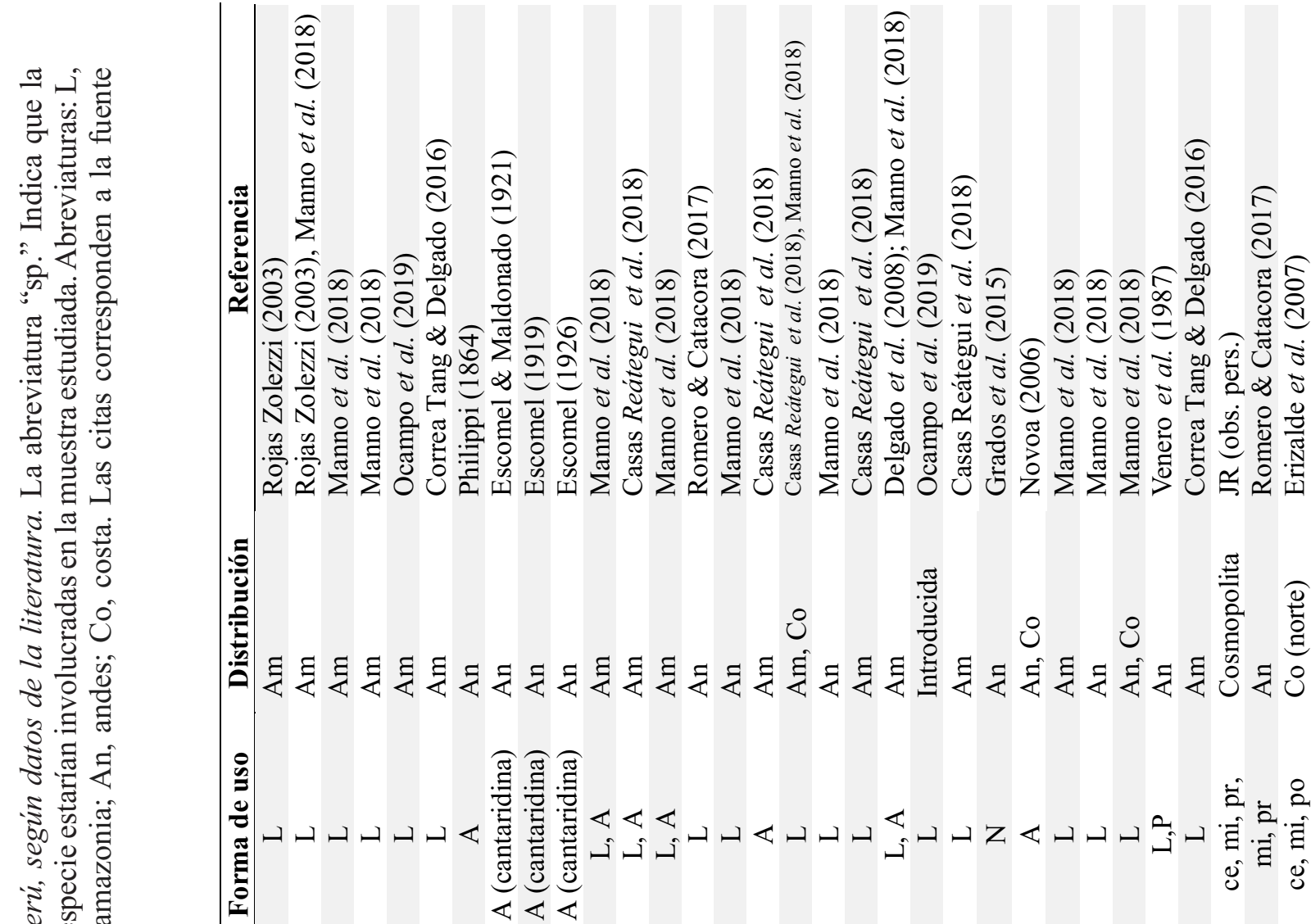

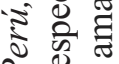

থ $\Xi$

\& 0

范

:

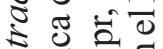

ฐ.尹

¿ 0.0

ई के ००

ᄀ光范

ป

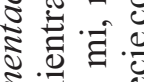

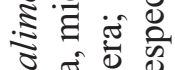

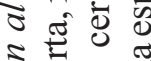

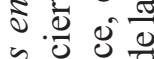

ปิ

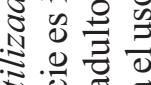

규 정

टे

:

๖요

㲞要

$\therefore$ 중

苋

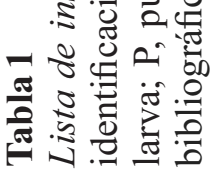

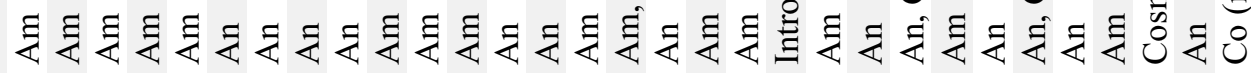

产.

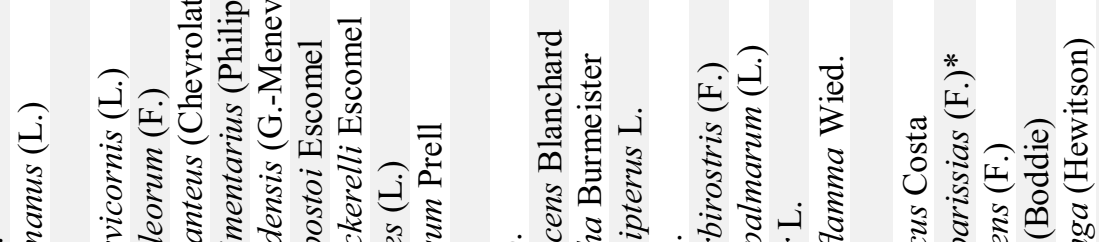

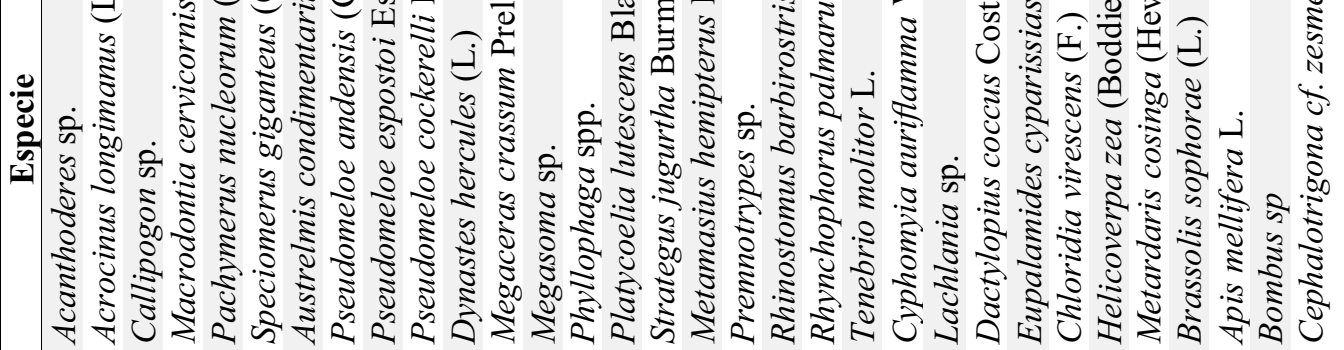

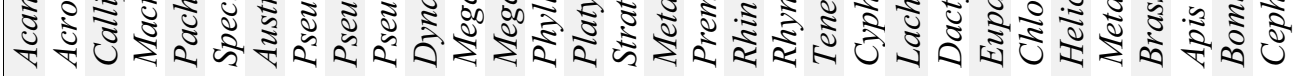

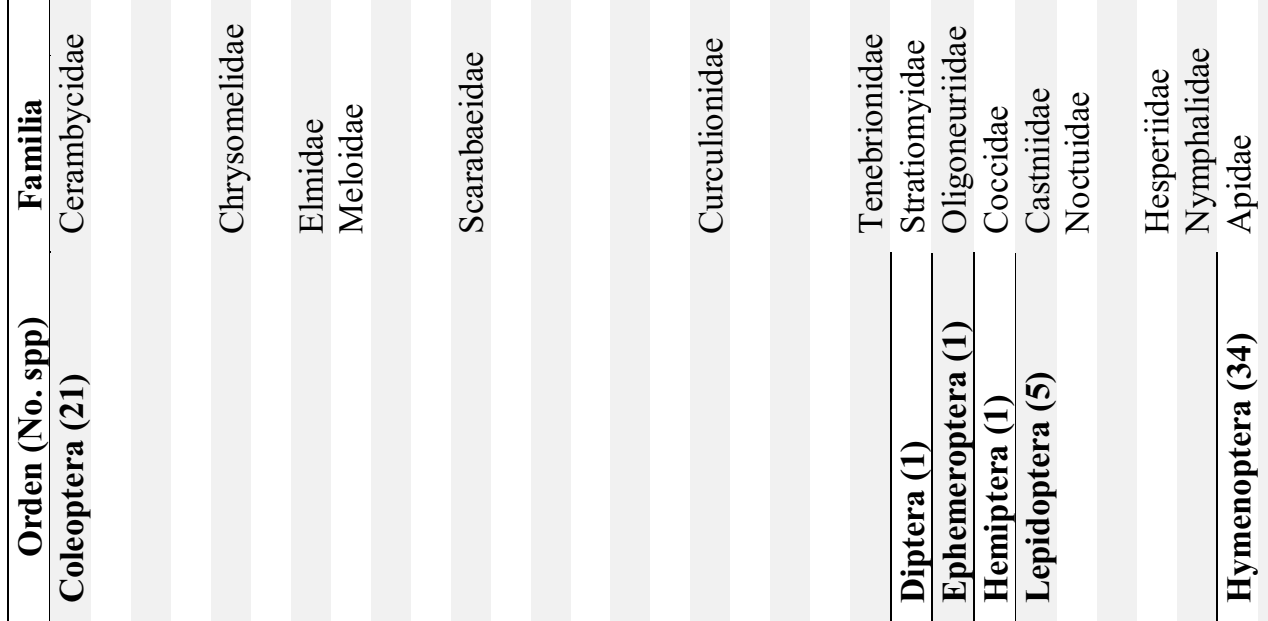

Ciencia \& Desarrollo, n. ${ }^{\circ 27}$, pp. 5-36 (2020) 


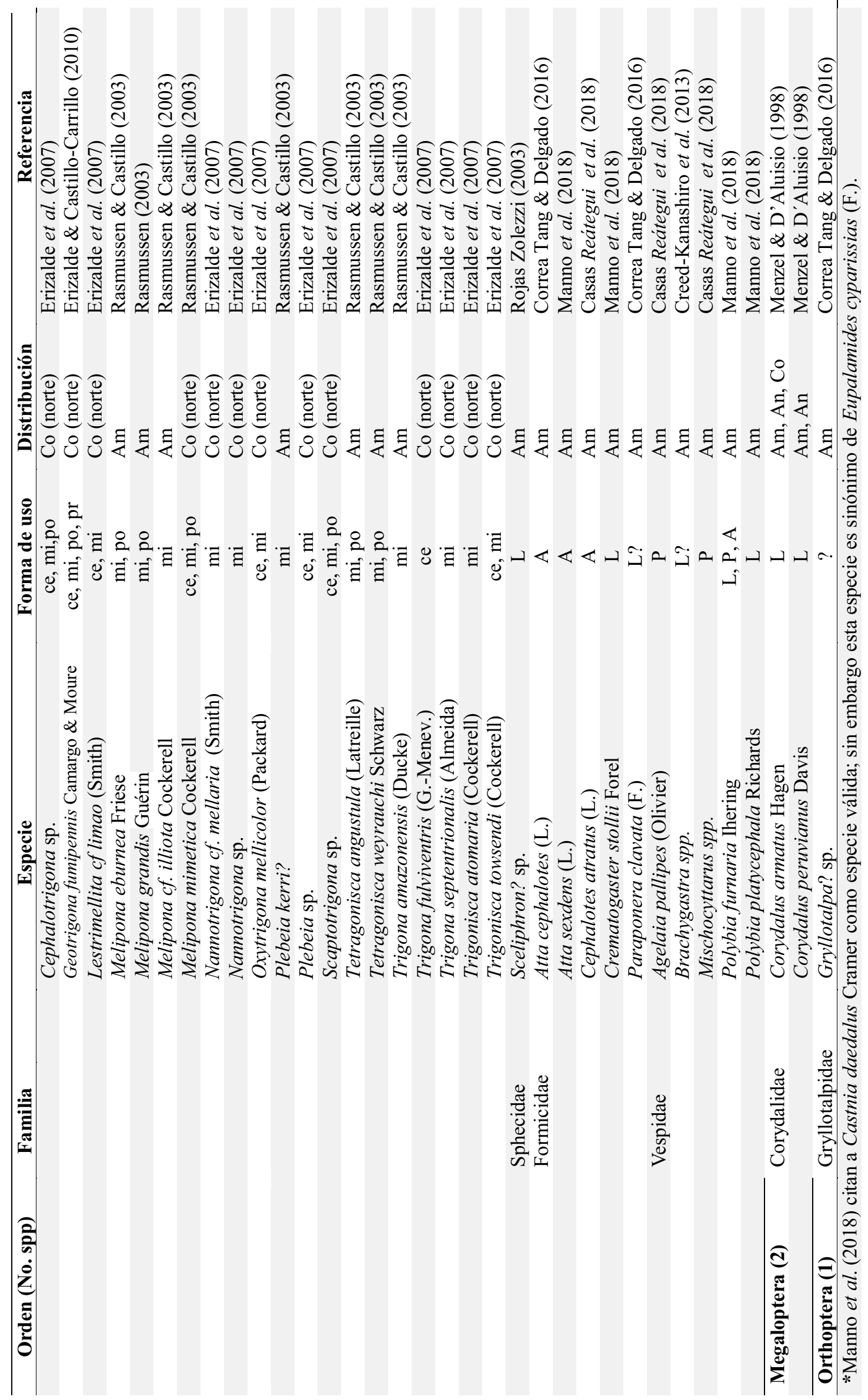

12 Ciencia \& Desarrollo, n. ${ }^{\circ} 27$, pp. 5-36 (2020) 
En Lepidoptera, la literatura reporta apenas cinco especies, entre las que destacan Metardaris cosinga, una mariposa Hesperiidae conocida en la región del valle del Río Urubamba en Cusco como "huaytampo" o "sucama", y asociada principalmente a Escallonia resinosa (Ruiz \& Pav.) Pers. o planta del "chachacomo" (Venero et al., 1987). Brassolis sophorae L. o "ahuihua" es otra especie de consumo difundido en la amazonia; sus larvas, asociadas a palmeras, son utilizadas en diversos tipos de preparaciones (Correa \& Delgado, 2016). Finalmente, Manno et al. (2018) documentaron el curioso caso del consumo de larvas de Helicoverpa zea (Boddie) y Chloridia virescens (F.), especies que se comportan como plaga y son de gran importancia en los agroecosistemas peruanos.

El resto de los insectos holometábolos reportados pertenecen a las órdenes Diptera y Megaloptera. En Diptera, Cyphomyia auriflamma Wiedemann y Hermetia illucens L. son las únicas dos especies de moscas comestibles conocidas del Perú, ambas en la familia Stratiomyidae. La primera es consumida en comunidades Awajún (Casas Reátegui et al., 2018), mientras que la segunda se trata de la "mosca soldado negra". El consumo de H. illucens en Perú no está explícitamente documentado en la literatura; sin embargo, esta es una de las especies más importantes en la emergente (y creciente) industria global de la entomofagia y su distribución nativa incluye el Perú (Iide \& Mileti, 1976). Finalmente, dos especies de Corydalus $(C$. armatus Hagen, y C. peruvianus Davis), en la orden Megaloptera, completan la lista de insectos holometábolos; las larvas de estas especies son depredadores acuáticos y habitan en ríos y quebradas (Menzel \& D'Alusio, 1998).

Los grupos de insectos no holometábolos están representados por Orthoptera, Hemiptera y Ephemeroptera. Correa Tang \& Delgado (2016) documentan el uso de Gryllotapa sp, un grillo topo en la familia Gryllotalpidae; sin embargo, Gryllotalpa no es un género distribuido en Sudamérica, por lo que este reporte quizá corresponda a alguna especie del género Neocurtilla o Scapteriscus erróneamente identificada. Aunque muchas especies de Hemiptera son consumidas globalmente, en el Perú el uso conocido de este grupo está restringido a Dactylopius coccus Costa. Mejor conocida como "cochinilla del carmín", esta especie se encuentra asociada al cactus Opuntia ficus-indica (L.) Mill o "tuna”, y tiene una larga tradición de uso en la región Andina, incluso desde tiempos preincaicos (Novoa, 2006). Perú es el principal productor mundial de cochinilla, aportando entre el $85 \%$ y el $90 \%$ de la demanda internacional; los extractos obtenidos de las cochinillas hembras se utilizan como colorante natural (rojo y derivados) en la industria alimentaria, cosmética y textil (Rodríguez et al., 2006). Por último, Grados et al. (2015) hacen un análisis histórico detallado del consumo tradicional de los "chíchi", insecto acuático cuya identidad fue establecida por los autores como una especie de Ephemeroptera en el género Lachlania (Oligoneuriidae); las ninfas de esta especie se extraen en grandes números de las quebradas altoandinas, siendo consumidas de manera tradicional en Cusco. Sin embargo, en quechua, chichi (var. "ch'ichi", "chhichi") es un sustantivo que también se emplea para designar múltiples objetos pequeños de ocurrencia simultánea. Según esta acepción, el término "chíchi" sería usado en sentido figurado para referirse colectivamente a los insectos acuáticos que se extraen de las quebradas y que representan una agrupación de múltiples unidades similares y pequeñas (una forma de entidad de masa no contable, categoría también asociada a los alimentos). En la descripción taxonómica de Austrelmis condimentarius (originalmente como Elmis condimentarius), Philippi (1864) menciona a este y otros tipos de insectos acuáticos (en este caso específico, Odonata, Ephemeroptera y hemípteros de la familia Corixidae) como ingredientes base del "chupe de chíchi". De este modo, es probable que el término "chíchi" se asocie, por antonomasia, a la comunidad de insectos acuáticos en general y usados como alimento, mas no necesariamente de manera específica a Lachlania sp. como plantearon Grados et al. (2015). Catacora \& Romero (2019) registran esta misma especie para la región del Altiplano de Puno, donde se conoce como "chhichi kuru" y es consumido con fines medicinales; sin embargo, Catacora \& Romero (2019) la asignan erróneamente al orden Hemiptera. 


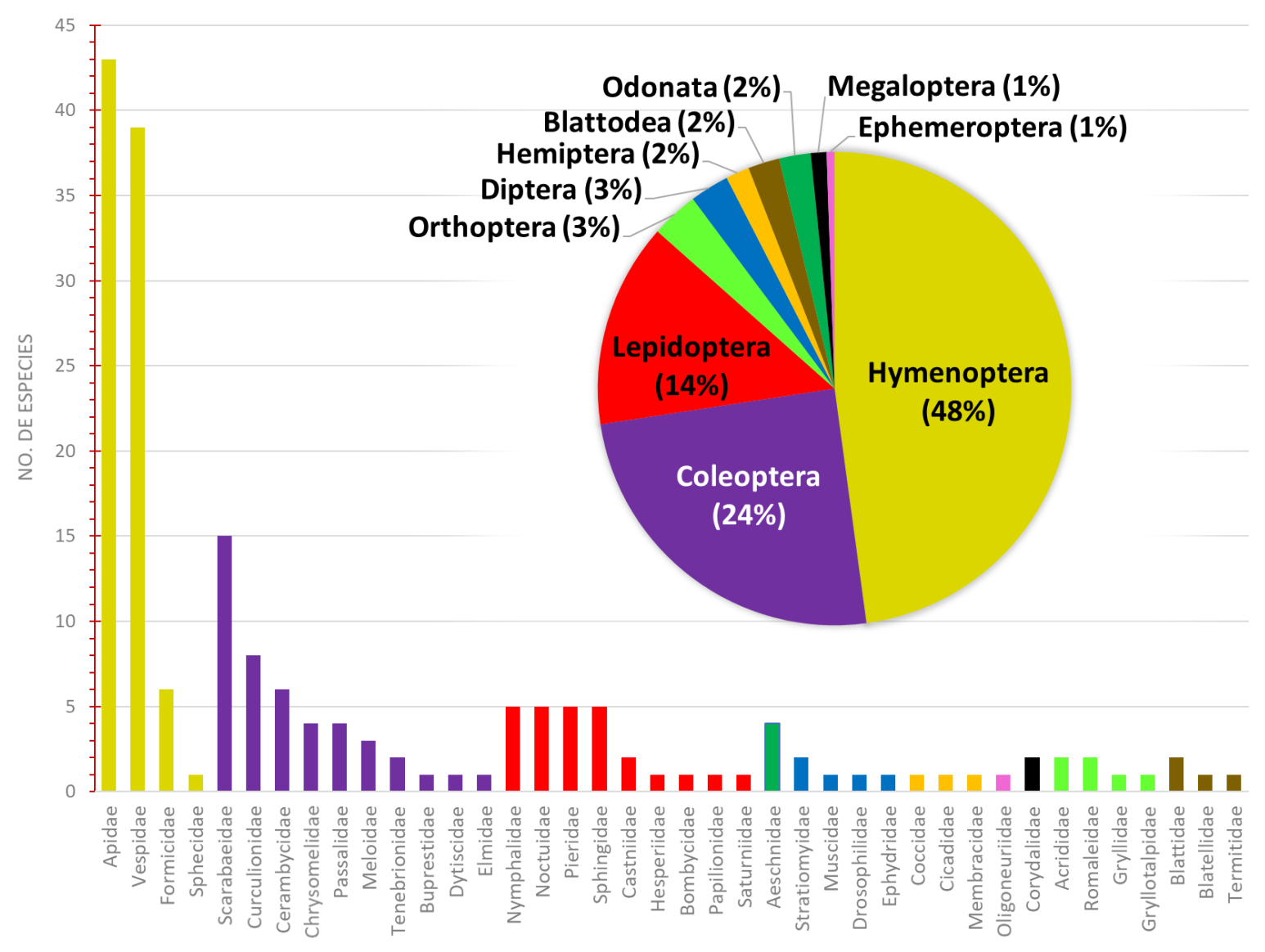

Figura 1. Diversidad de insectos comestibles del Peru (Tablas 1 y 2 combinadas). Las ordenes Hymenoptera, Coleoptera y Lepidoptera representan juntos el 86\% (161 spp.) del total de especies comestibles reportadas en este estudio (186 spp.). Hymenoptera destaca como el grupo con mayor número de especies utilizables, sobre todo aquellas de las familias Vespidae y Apidae. En la primera destaca el uso marcado de representantes de la familia Vespidae, notablemente de la subfamilia Polistinae, avispas eusociales que suelen construir nidos de papel donde albergan cientos y hasta miles de individuos en diferentes fases de desarrollo. Por otro lado, Apidae está mayormente representada por abejas sin aguijón de la tribu Meliponini, las cuales son sujetas a prácticas de manejo para la obtención de miel y otros derivados. Coleoptera (escarabajos) es el grupo taxonómicamente más diverso, mientras que dentro de Lepidoptera tanto larvas de polillas como mariposas son consumidas.

Se encontró que algunas de las identificaciones taxonómicas reportadas en la literatura eran equívocas. Por ejemplo, Romero \& Catacora (2017) citan una especie del género Macromia (Odonata) que es consumida en el Altiplano. Sin embargo, este género es nativo de Europa y no ocurre en Sudamérica. La comunidad de insectos acuáticos de la región altiplánica se caracteriza por su baja diversidad de Odonata; solo dos géneros ocurren: Protallagma (Coenagrionidae, 1 especie) y Rhionaeschna (Aeshnidae, 4 especies). Onore (2007) reportó el consumo de $R$. brevifrons (Hagen), $R$. marchali (Rambur) y $R$. peralta (Ris) en Ecuador, especies que también se encuentran distribuidas en la región altiplánica (von Ellenrieder, 2003), por lo que es posible que el reporte de Romero \& Catacora (2017) sea referible a alguna de estas especies. Del mismo modo, Casas Reategui et al. (2018) reportan a Crematogaster sordidula (Nylander), siendo utilizada como alimento por comunidades Awajún en el departamento de Amazonas. Sin embargo, esta hormiga es nativa de Europa y no ocurre en Sudamérica (AntWeb; https://www.antweb.org); este registro requiere verificación. Otro reporte evidentemente espurio es el de Stenodontes damicornis (Coleoptera: Cerambycidae) por Steward \& Métraux (1963), una especie restringida a las Antillas Mayores. Las especies mencionadas no han sido incluidas en la lista de especies consumidas en el Perú debido a incertidumbres en su identificación taxonómica. 


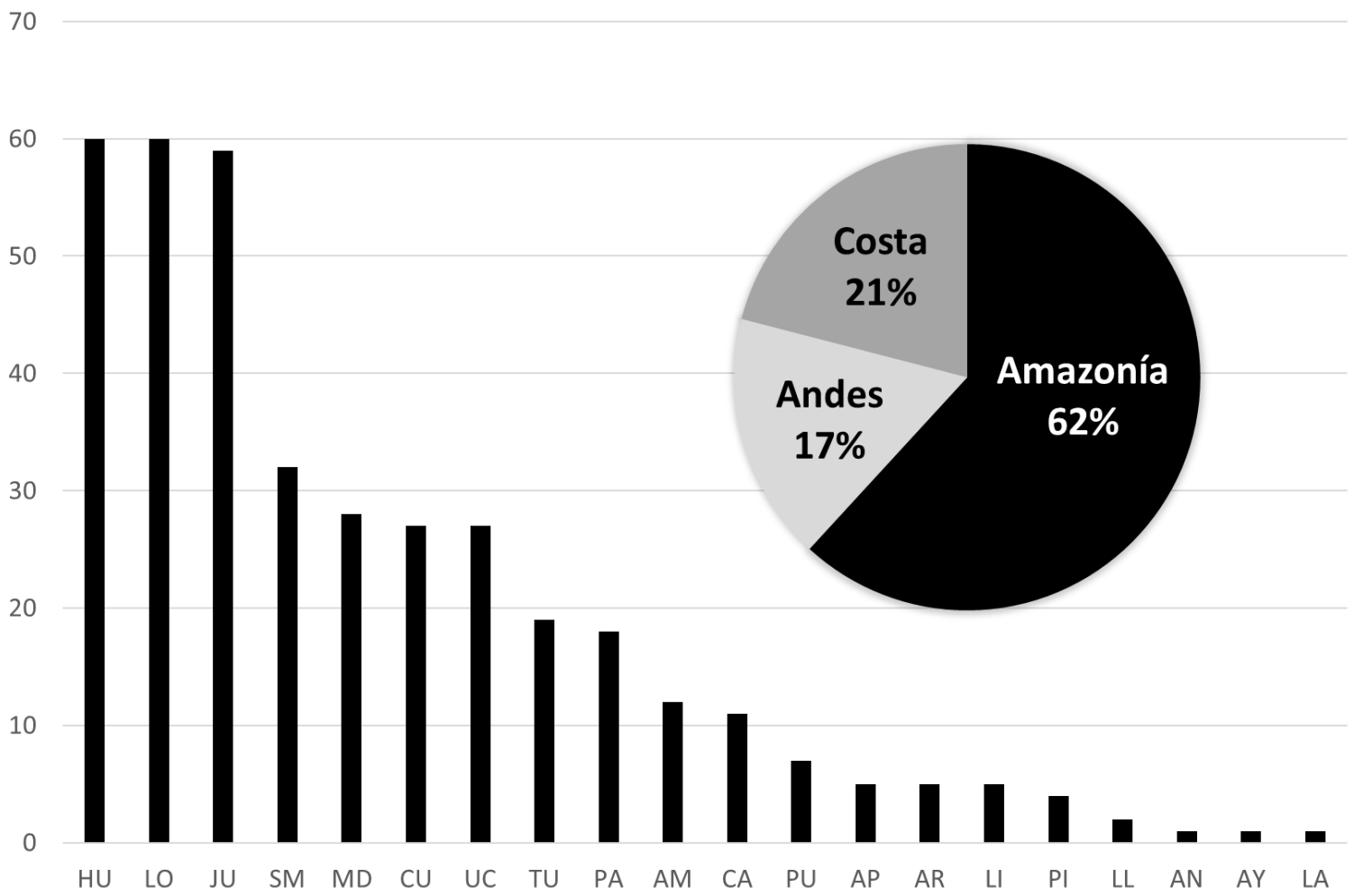

Figura 2. Distribución geográfica de la biodiversidad de insectos comestibles del Peru (Tablas 1 y 2 combinadas). La Amazonía, como es de anticipar, muestra la mayor diversidad, siendo Huánuco (HU), Loreto (LO) y Junín (JU) los departamentos con mayor biodiversidad de especies utilizables. La Costa es segunda en especies, pero buena parte de estas se concentran en los departamentos de Tumbes (TU) y Piura (PI), cuyo clima tropical y vegetación variada favorecen la proliferación de abejas meliponas (meliponicultura). Finalmente, aunque la región Andina cuenta con escasos registros estos están principalmente concentrados en los Andes del sur y la zona altiplánica, regiones donde diversas prácticas tradicionales relacionadas al consumo de insectos aún persisten. Otras abreviaturas (departamentos): AM, Amazonas; AN, Áncash; AP, Apurímac; AR, Arequipa; AY, Ayacucho, CA, Cajamarca; CU, Cusco; LA, Lambayeque, LI, Lima: LL, La Libertad; MD, Madre de Dios; PA, Pasco; PU, Puno; SM, San Martin; UC, Ucayali.

El número de especies de insectos utilizados directa e indirectamente (66 spp.) es relativamente bajo si se compara con regiones vecinas. Por ejemplo, Onore (1997) reportó 83 especies utilizadas en Ecuador, un país similar a Perú desde el punto faunístico, pero relativamente menos diverso en función de su área geográfica. Sin embargo, luego de contrastar la lista de insectos comestibles del mundo (Jongema, 2017) con datos de distribución geográfica de las especies de origen Neotropical (y cosmopolitas) incluidas en dicha lista, se halló que existen al menos 120 especies adicionales (Tabla 2) cuyo consumo ha sido reportado en países limítrofes y cuya distribución geográfica también incluye el Perú, aunque su uso en este país no ha sido formalmente documentado. Esto eleva el número total de especies de facto (y potencialmente) utilizables a un mínimo de 186 (Figura 1). Este incremento notable no es de sorprender, ya que los estudios que dan cuenta del consumo y utilización de insectos en Perú han sido extremadamente limitados. La mayor diversidad de especies se encuentra naturalmente en la región Amazónica, seguido de la Costa y finalmente la región Andina (Figura 2). La forma de uso puede ser consumo directo (de forma integral o como parte de un preparado) o indirecto, a través de derivados, tales como las mieles, polen, cera y propóleos (Figura 3). Las especies aquí documentadas sin duda representan solo una parte de aquellas que son de facto utilizadas, o tienen potencial de uso (directo y/o indirecto), en el Perú. 


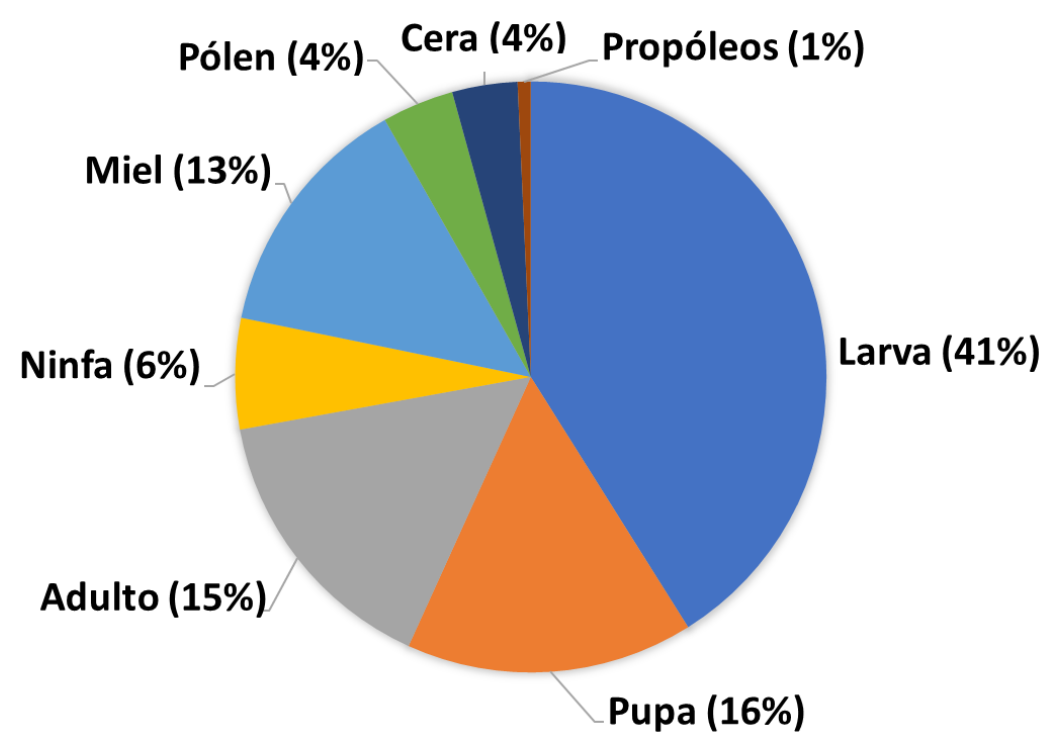

Figura 3. Formas de uso principal (consumo directo y derivados). El 41\% de las de las especies (Tablas 1 y 2 combinadas) son utilizadas en su forma larval, el estadío de desarrollo de consumo preferente (en virtud de su mayor contenido nutricional y digestibilidad). El 13\% de especies son valoradas por su producción de miel, principalmente abejas meliponas. 


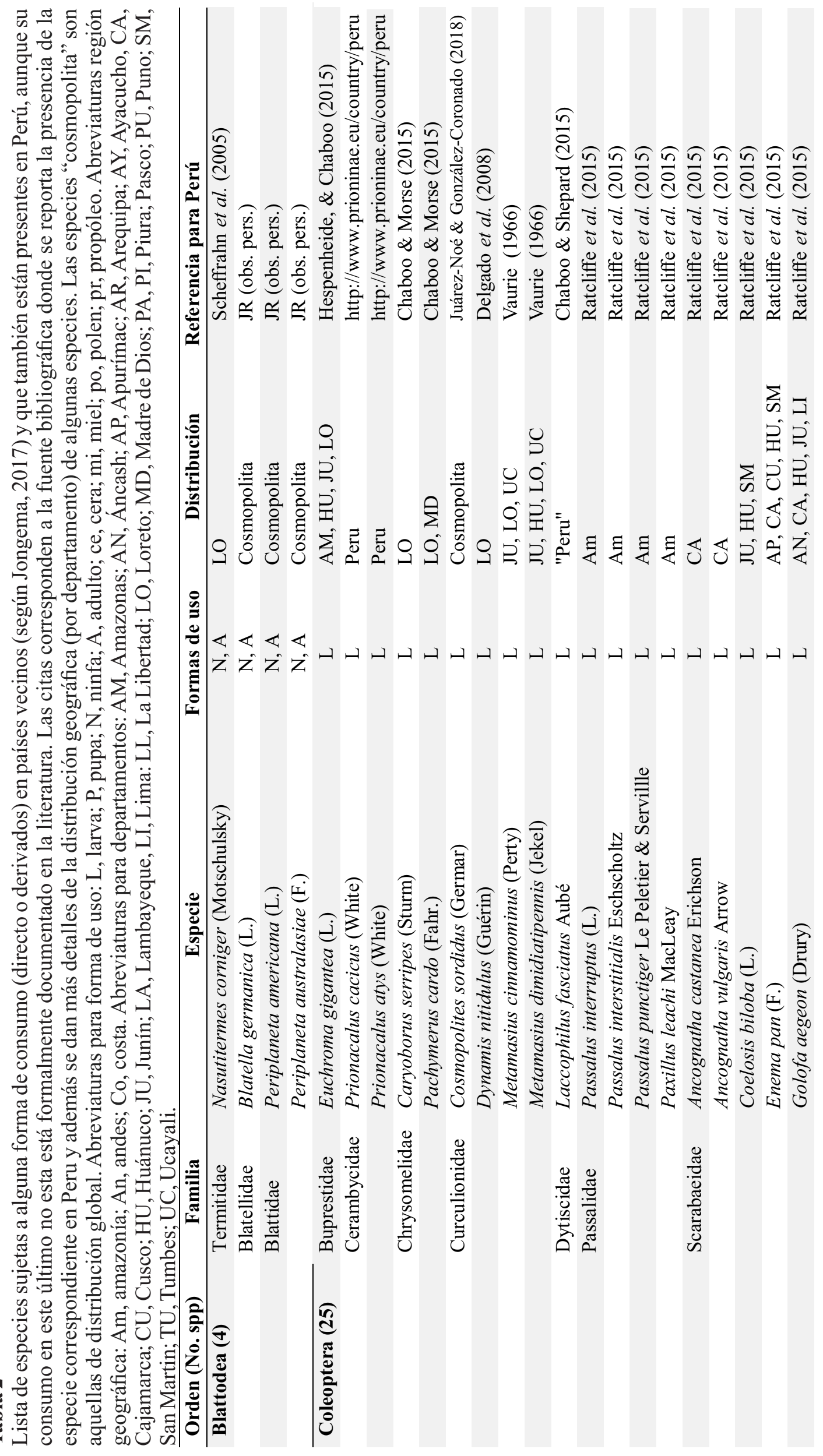

Ciencia \& Desarrollo, n. ${ }^{\circ 27}$, pp. 5-36 (2020) 


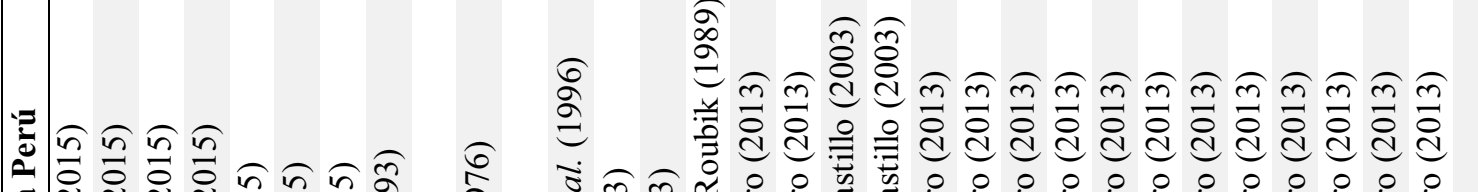

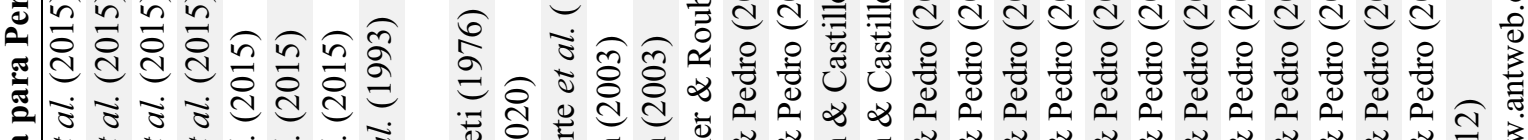

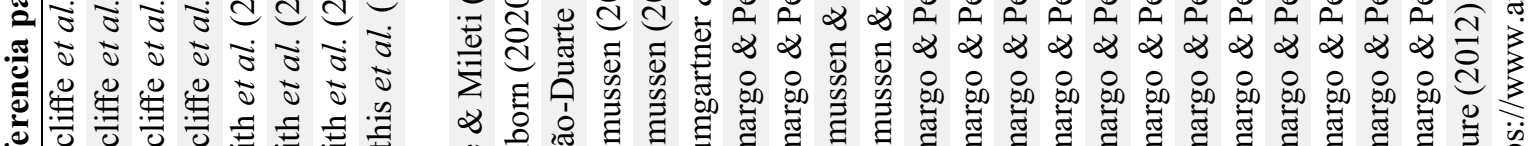

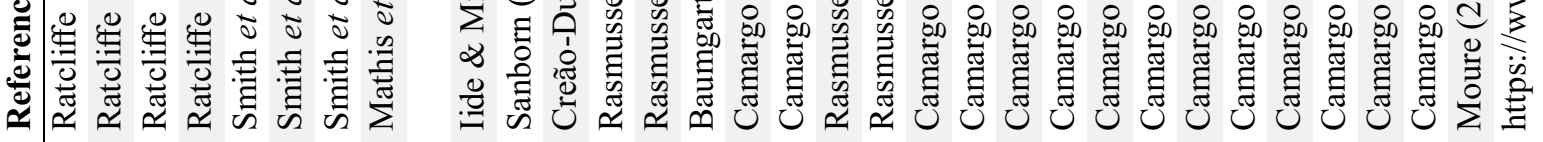

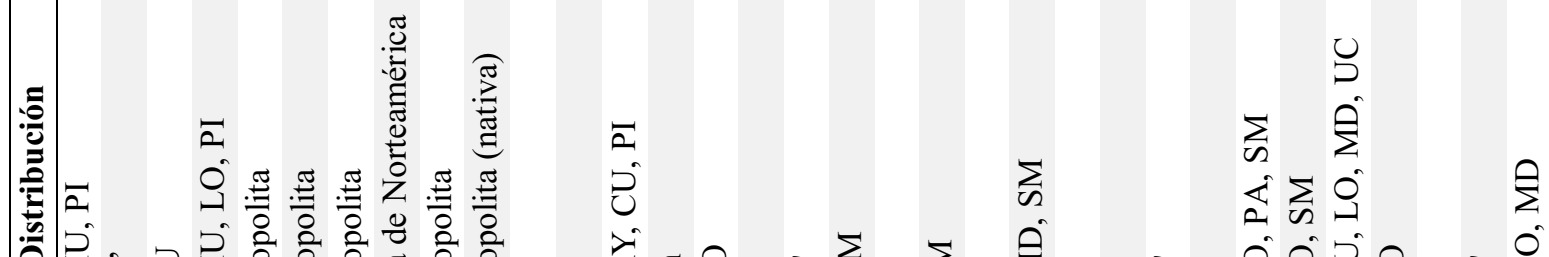

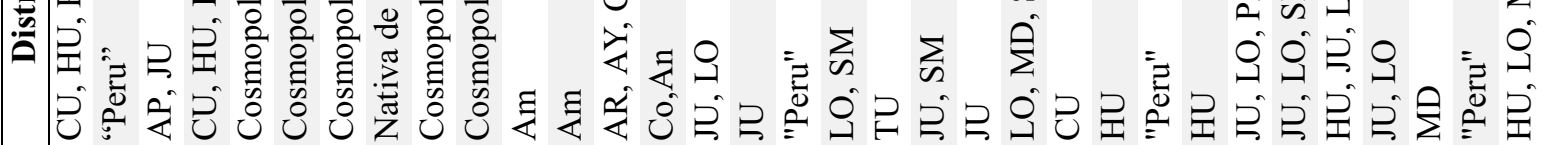

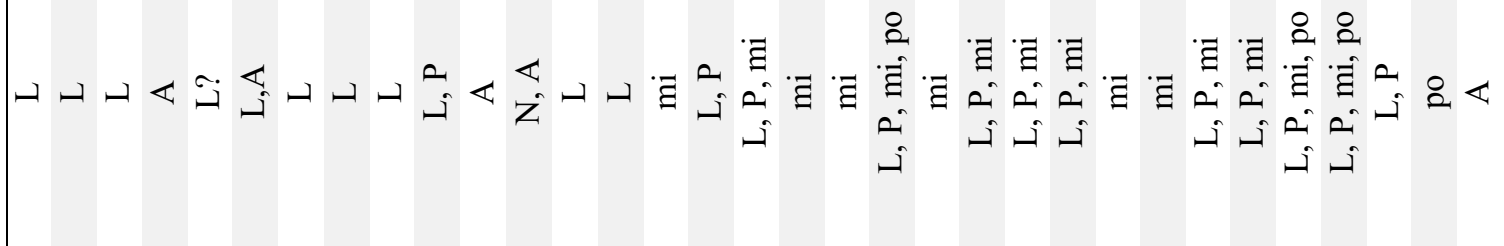

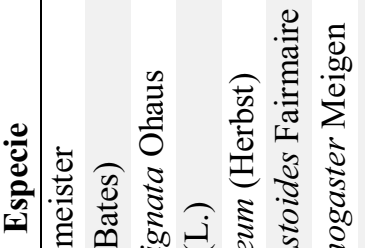

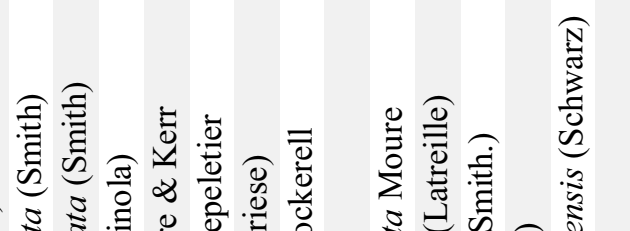

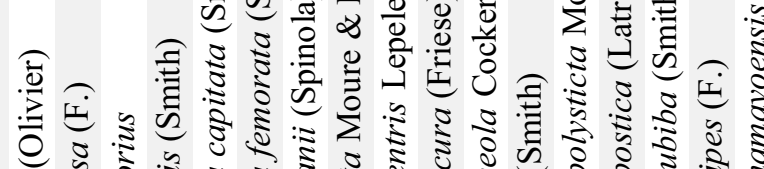<smiles>C[C@H]1C[C@@H]1C</smiles>

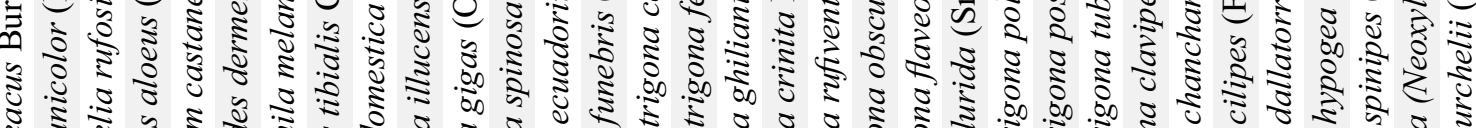

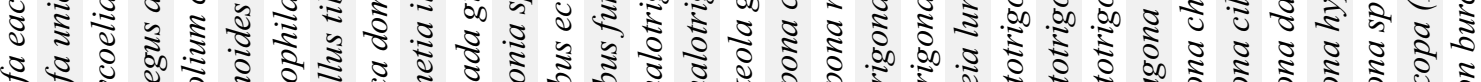
क. จ.

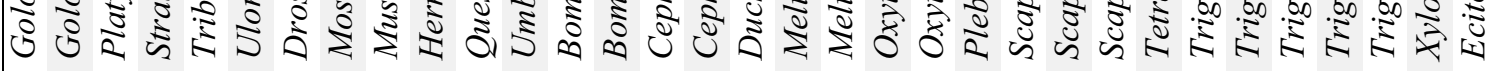
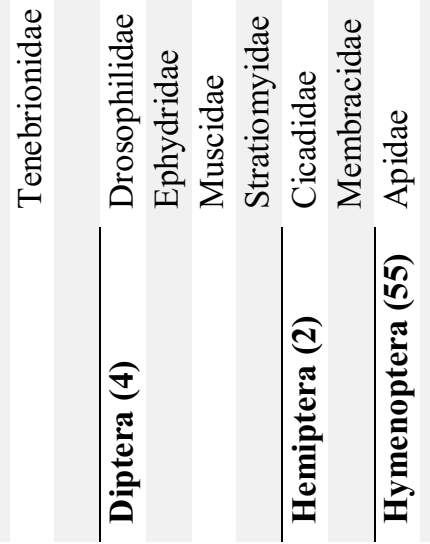

18 Ciencia \& Desarrollo, n. ${ }^{\circ} 27$, pp. 5-36 (2020) 


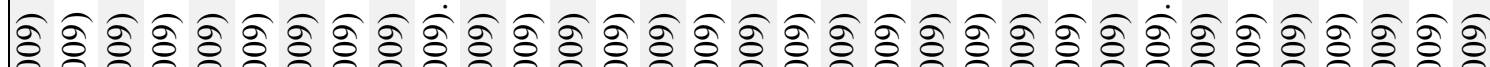

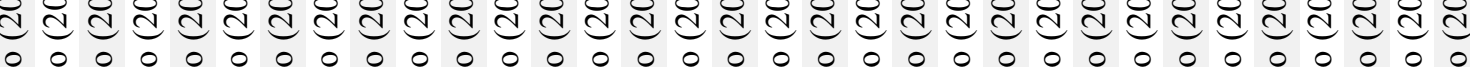

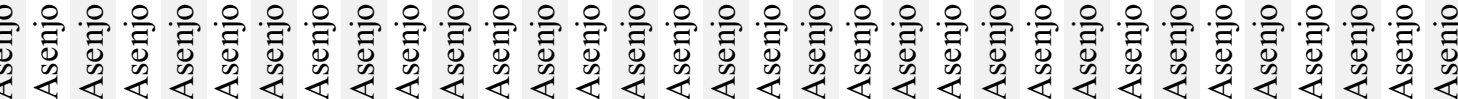

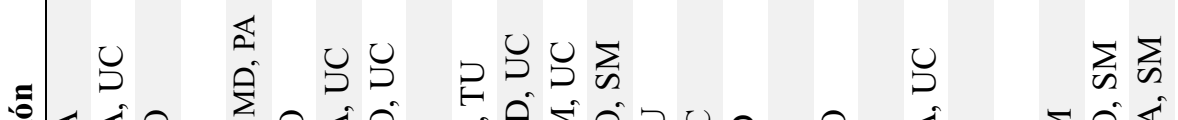

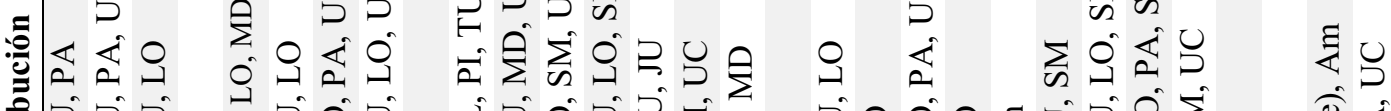

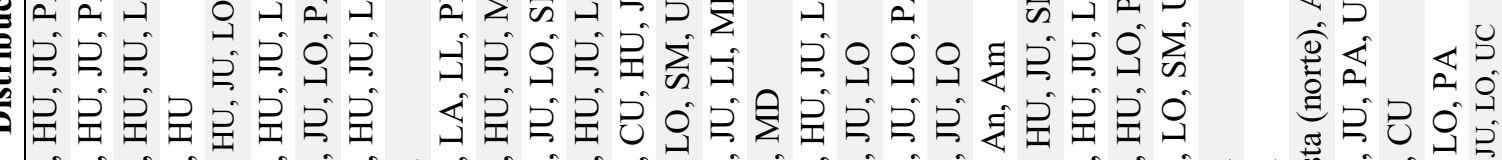

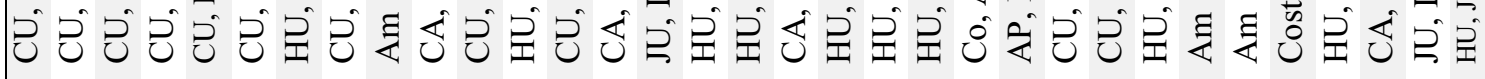

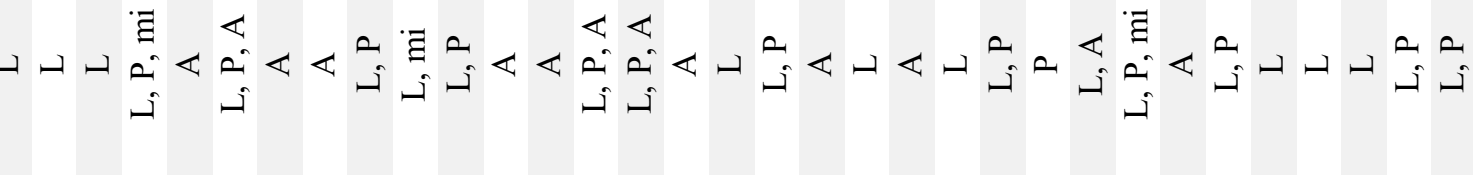

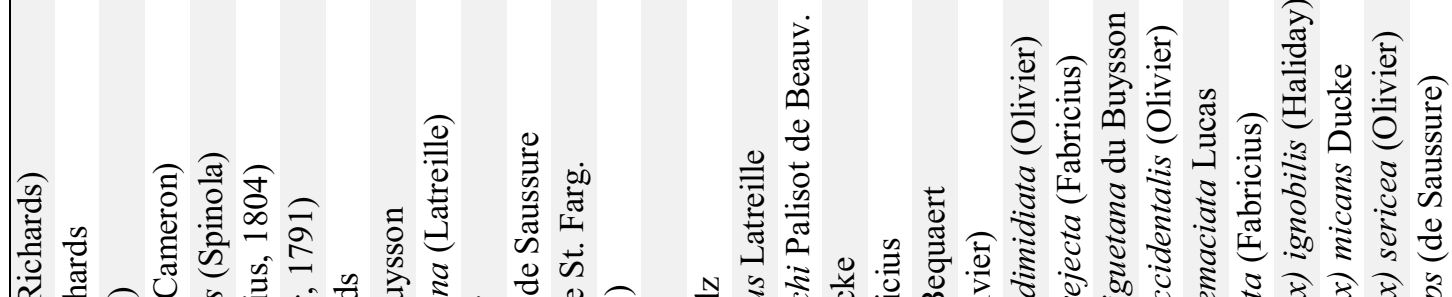

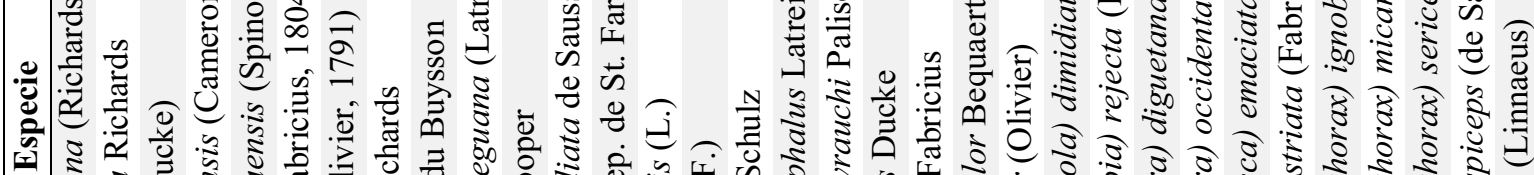

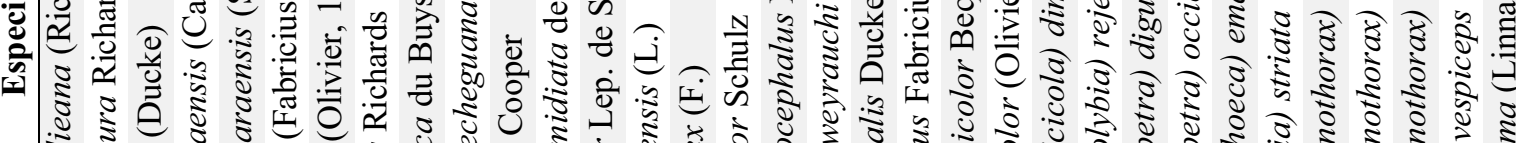

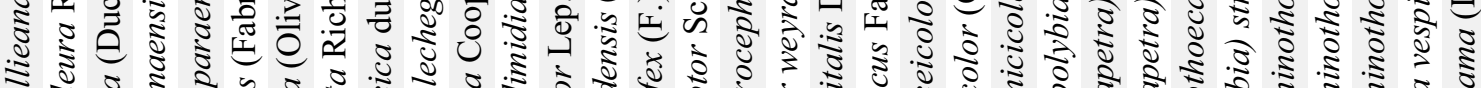

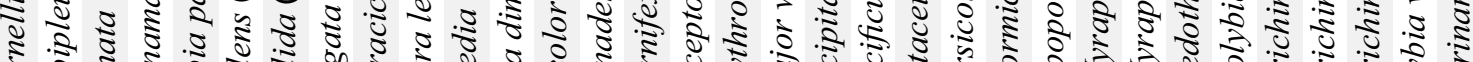

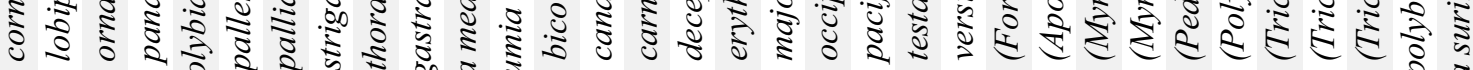

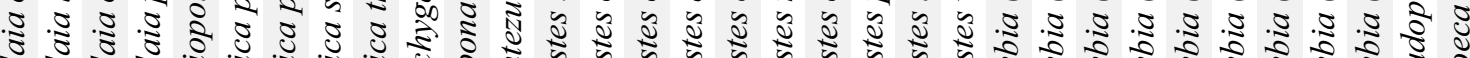

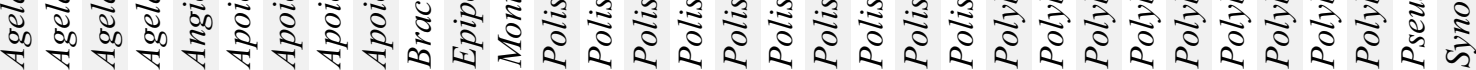




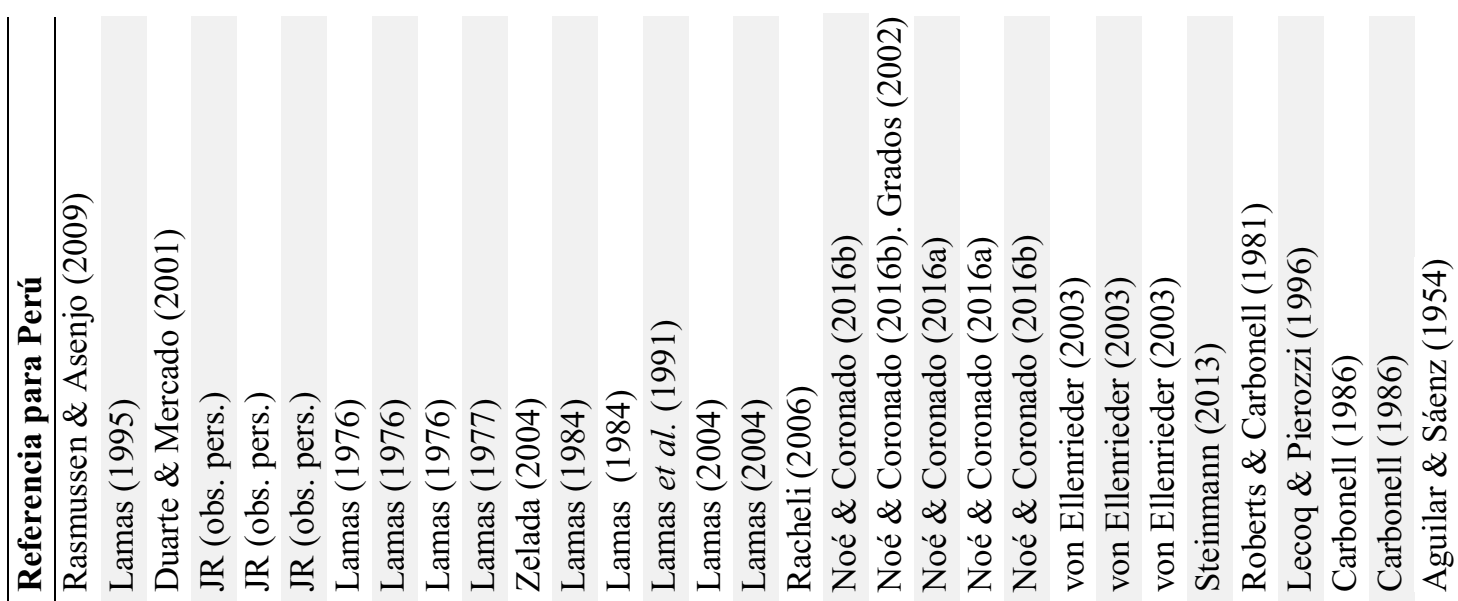

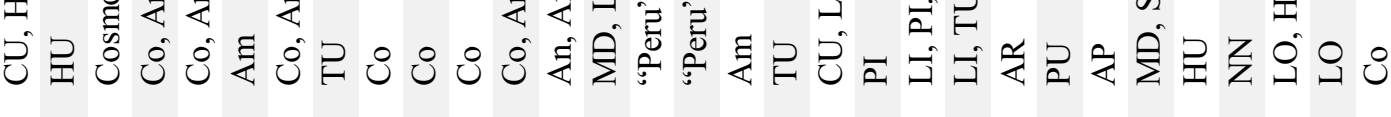

胥

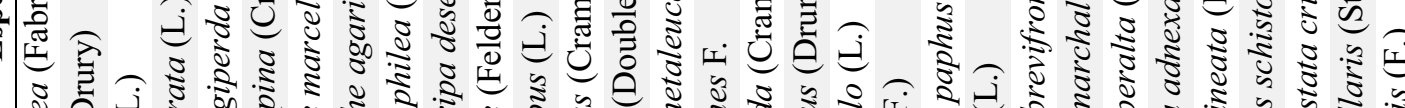

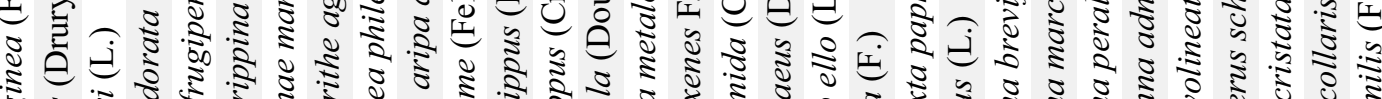

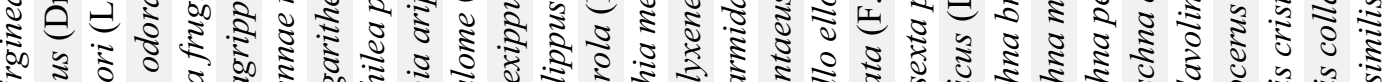

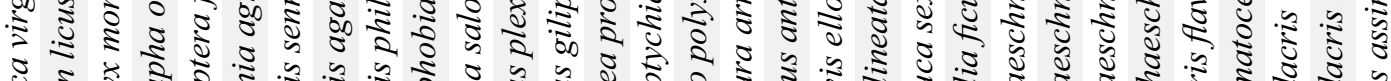

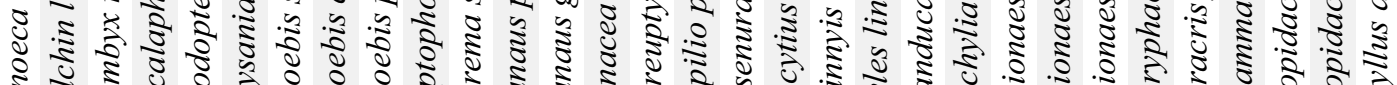

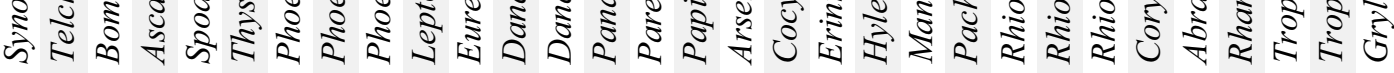

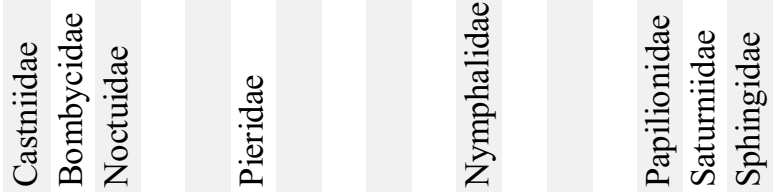

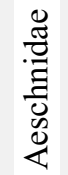
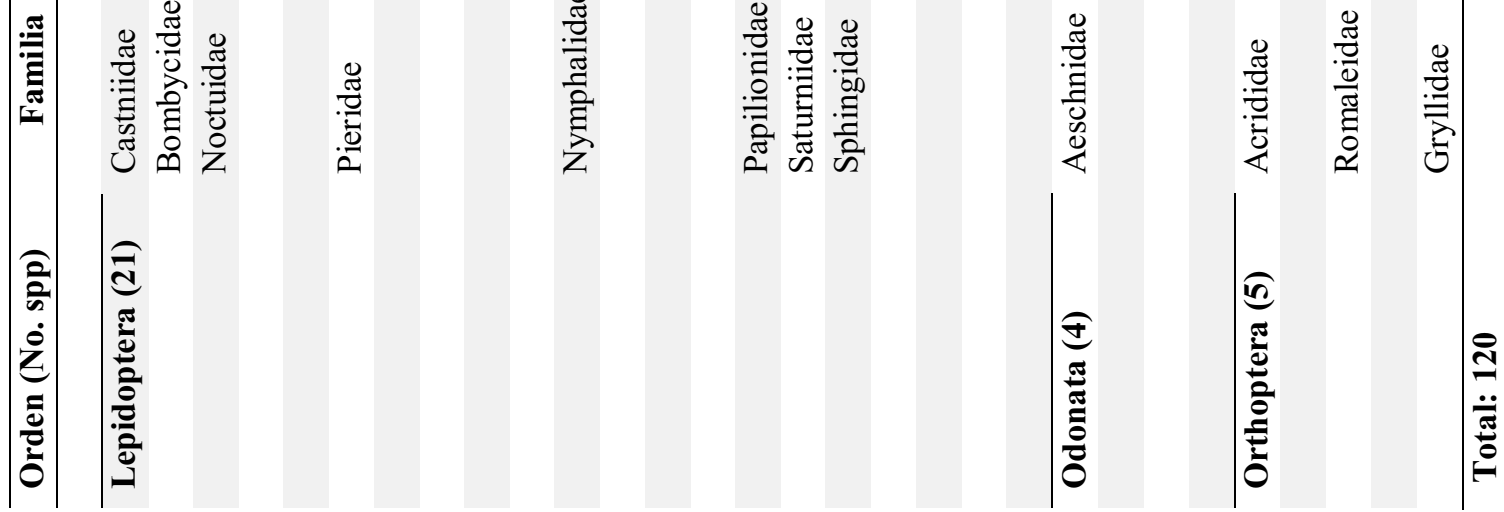

20 Ciencia \& Desarrollo, . $^{\circ} 27$, pp. 5-36 (2020) 


\section{Rol de los insectos en la seguridad alimentaria y sostenibilidad ambiental}

El crecimiento de la población mundial resulta en un aumento en la demanda por nutrientes clave para el desarrollo y salud óptimos. Según la ONU, se proyecta que a la tasa de crecimiento actual, la población mundial alcanzará los 9.7 billones a mediados del 2050. A partir de este incremento, se estima que el consumo de productos agrícolas y de origen animal para entonces aumentarán en un $110 \%$ y 60-70\% , respectivamente (Tilman et al., 2011; Makkar et al., 2014). Un incremento en la demanda por nutrientes se traducirá en una degradación ambiental sustancial para satisfacer la demanda de la población en aumento, por lo que será necesario transformar áreas de vegetación natural en zonas ganaderas para poder incrementar la oferta de nutrientes (Tilman et al., 2001). A esto se suman otros pasivos ambientales colaterales que ya constituyen motivo de alarma: emisión de gases de efecto invernadero, degradación de la tierra, contaminación del aire y agua, sobreexplotación y pérdida de biodiversidad terrestre y marina (Tilman et al., 2011; Mekonnen y Hoekstra, 2012; Steinfeld et al., 2006). Las soluciones técnicas orientadas a desarrollar prácticas agropecuarias más eficientes y sostenibles no serán suficientes para superar los desafíos ambientales surgidos en busca de la seguridad alimentaria en tiempo de transformación climática (Ericksen et al., 2009; Wheeler \& Von Braun, 2013). Por lo tanto, resulta imprescindible la búsqueda de fuentes sostenibles de nutrientes para la producción de alimento humano y animal, que al mismo tiempo sean parte de una estrategia integral que busque prevenir un mayor deterioro ambiental (Tilman \& Clark, 2014).

Diversas voces a nivel global argumentan que los insectos jugarán un papel importante en el futuro de la seguridad alimentaria. De hecho, la FAO publicó en 2013 un reporte sobre el rol que tendrán los insectos en la nutrición humana de cara al cambio climático (Van Huis et al, 2013), proceso que ya impacta la producción, distribución y acceso a nutrientes de calidad. Por su alto contenido de proteínas (10-63 \% por unidad de peso, dependiendo de la especie y sustrato de alimentación), los insectos compiten con otras fuentes proteicas como las aves de corral y la carne de res, además contienen importantes cantidades de ácidos grasos poliinsaturados incluyendo los esenciales (especialmente en forma larval y en algunos casos pupal), antioxidantes, vitaminas (tiamina, ácido fólico, riboflavina, biotina, ácido pantoténico) y micronutrientes como el calcio, fósforo, hierro, manganeso, magnesio, selenio, zinc, todos fundamentales para un crecimiento y desarrollo de funciones cognitivas óptimos (Rumpold \& Schlüter, 2013; Paul et al., 2017; Zielińska et al., 2018; Mwangi et al., 2018) (Tabla 3). La producción y consumo de insectos supone también una serie de beneficios ambientales en comparación a las fuentes convencionales de proteínas. Por ejemplo, la crianza masiva de insectos requiere comparativamente menos espacio, agua y forraje, resulta en una notable reducción en la emisión de gases de efecto invernadero, además, muchas especies pueden ser alimentadas y reproducidas rápida y eficientemente con residuos orgánicos diversos, viabilizando así ciclos económicos circulares de valor agregado (Oonincx et al., 2010; Van Huis et al., 2013; Mlcek et al., 2014; Ojha et al., 2020). Los insectos muestran también un gran potencial como fuente alternativa de proteína para la producción de alimento destinado a animales de granja y piscicultura (e.g. Cummins et al., 2017; Stadtlander et al., 2017; Devic et al., 2018; Pieterse et al., 2019). De este modo, los insectos representan un recurso alternativo altamente viable para también suplir las dietas de animales destinados a consumo humano con proteína sostenible y de alta calidad. 
Tabla 3

Composición química de especies representativas

\begin{tabular}{|c|c|c|c|c|}
\hline Especie [Orden taxonómico] & $\begin{array}{c}\text { Proteína } \\
(\%)^{1}\end{array}$ & $\begin{array}{c}\text { Grasas totales } \\
(\%)^{1}\end{array}$ & $\begin{array}{c}\text { Energía } \\
\text { (Kcal/100g) }\end{array}$ & Ref. \\
\hline Lachlania sp. [Ephemeroptera] & 42.79 & 34.73 & - & Catacora \& Romero (2019) \\
\hline Gryllus assimilis [Orthoptera] & $49.55-75$ & 20.24 & - & Blanco et al (2020); Vera Cedeño (2020) \\
\hline Atta cephalotes [Hymenoptera] & $43-60.11$ & $25.8-31$ & $390-580$ & Casas Reátegui et al (2018) \\
\hline Hermetia illucens [Diptera] & $17.5-47$ & $14-32.6$ & 199 & Zielinska et al. (2018) \\
\hline Rhynchophorus palmarum [Coleoptera] & $25.8-28$ & $38.5-46$ & 583 & Cerda et al (2001); Ocampo et al. (2019) \\
\hline Pachymerus nucleorum [Coleoptera] & $30.8-37.87$ & $37.87-65.3$ & $710-473$ & Alves et al. (2018); Ocampo et al (2019) \\
\hline Tenebrio molitor [Coleoptera] & $11.42-68.6$ & $5.4-43.8$ & $130.61-577.44$ & Zielinska et al. (2018) \\
\hline \multicolumn{5}{|l|}{ Otros alimentos de consumo regular } \\
\hline Carne animal ${ }^{2}$ & $11.2-22.8$ & $18.4-21.4$ & $97-322$ & www.fao.org \\
\hline Huevo de gallina & $12-13$ & 11.2 & 158 & www.fao.org \\
\hline Leche de vaca & 3.3 & 3.3 & 61 & www.fao.org \\
\hline
\end{tabular}

${ }^{1}$ porcentaje por unidad de peso

${ }^{2}$ Res, cerdo, pollo y pescado (valores combinados)

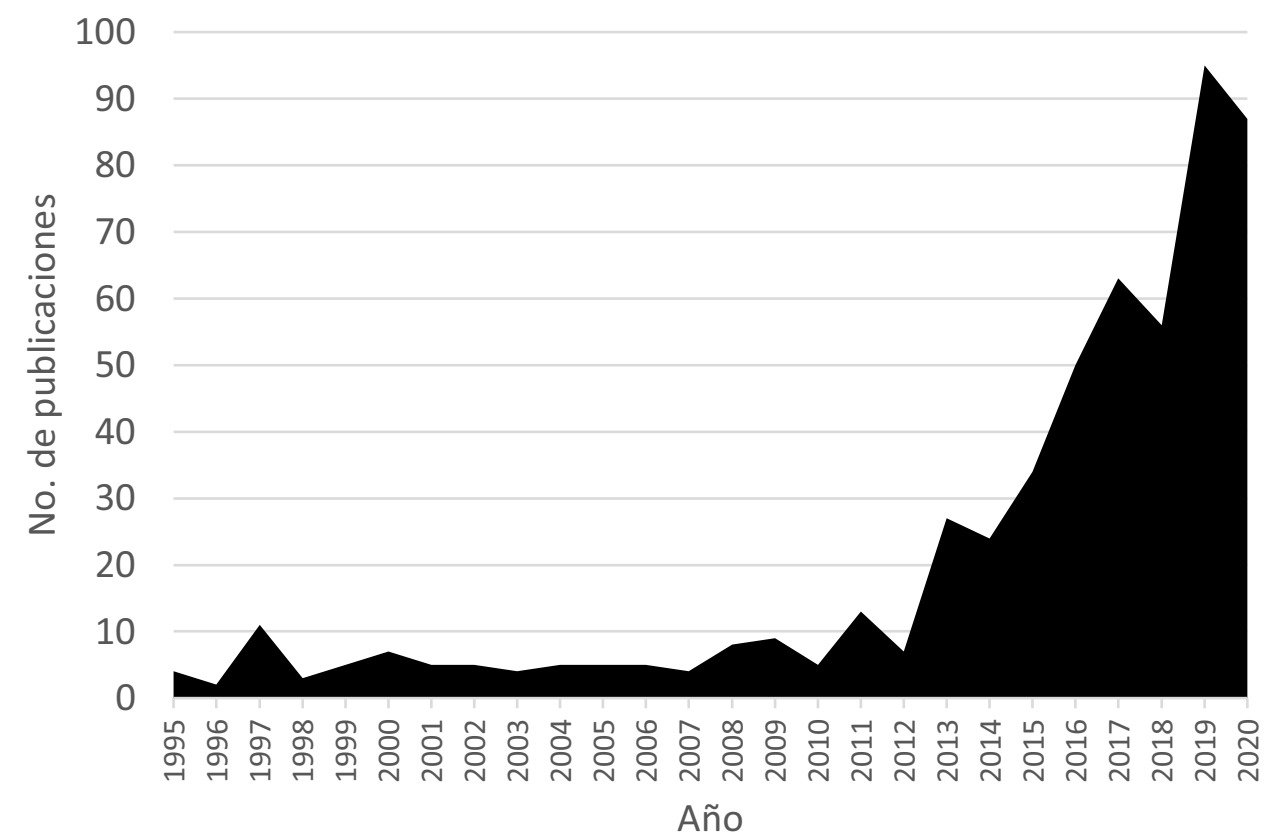

Figura 4. Producción científica global sobre insectos comestibles entre 1995-2020 (Octubre). A partir del año 2013 el número de publicaciones experimenta un incremento importante y sostenido hasta el 2020; en este período de 7 años el número de publicaciones fue cuatro veces mayor que los producidos en los 17 años anteriores (1995-2012). Los ámbitos de mayor indagación científica incluyen las ciencias de los alimentos, nutrición, agricultura y química aplicada. Fuente: Web of Science. 
Como resultado de los esfuerzos de la FAO en promover la entomofagia (van Huis et al, 2013), el estudio de los insectos comestibles ha recibido considerable interés por parte de la comunidad científica, especialmente la industria de alimentos (Patel et al., 2019). Un análisis de la producción científica global muestra un incremento notable de estudios asociados a la entomofagia en la última década (Figuras 4-5). El creciente interés de los países occidentales por desarrollar industrias sostenibles ha fomentado la idea de que los insectos representan "el futuro de la alimentación", slogan que ha incentivado el escrutinio de las propiedades organolépticas y funcionales de los insectos con el objetivo de favorecer su procesamiento y palatabilidad, ya sea como alimento integral o suplemento fortificante (Glover \& Sexton, 2015). Las sustancias que muchos insectos producen y que son utilizadas en medicina tradicional alrededor del mundo pueden ser también de interés a la industria farmacéutica (Oghenesuvwe \& Paul, 2019), aunque esta dimensión de la entomofagia ha recibido menos atención por parte de la ciencia occidental y más estudios son requeridos para demostrar los beneficios que la etnomedicina atribuye a estos organismos (Kim et al., 2019). En vista del creciente interés por fuentes sostenibles de alimentos varios países, prominentemente occidentales, vienen adecuando su marco legal para promover el ingreso de "entomoproductos" al mercado. Por ejemplo, la UE y países como Canadá y EEUU ya regulan el uso de insectos (prominentemente Hermetia illucens) como aditivo para pienso animal.

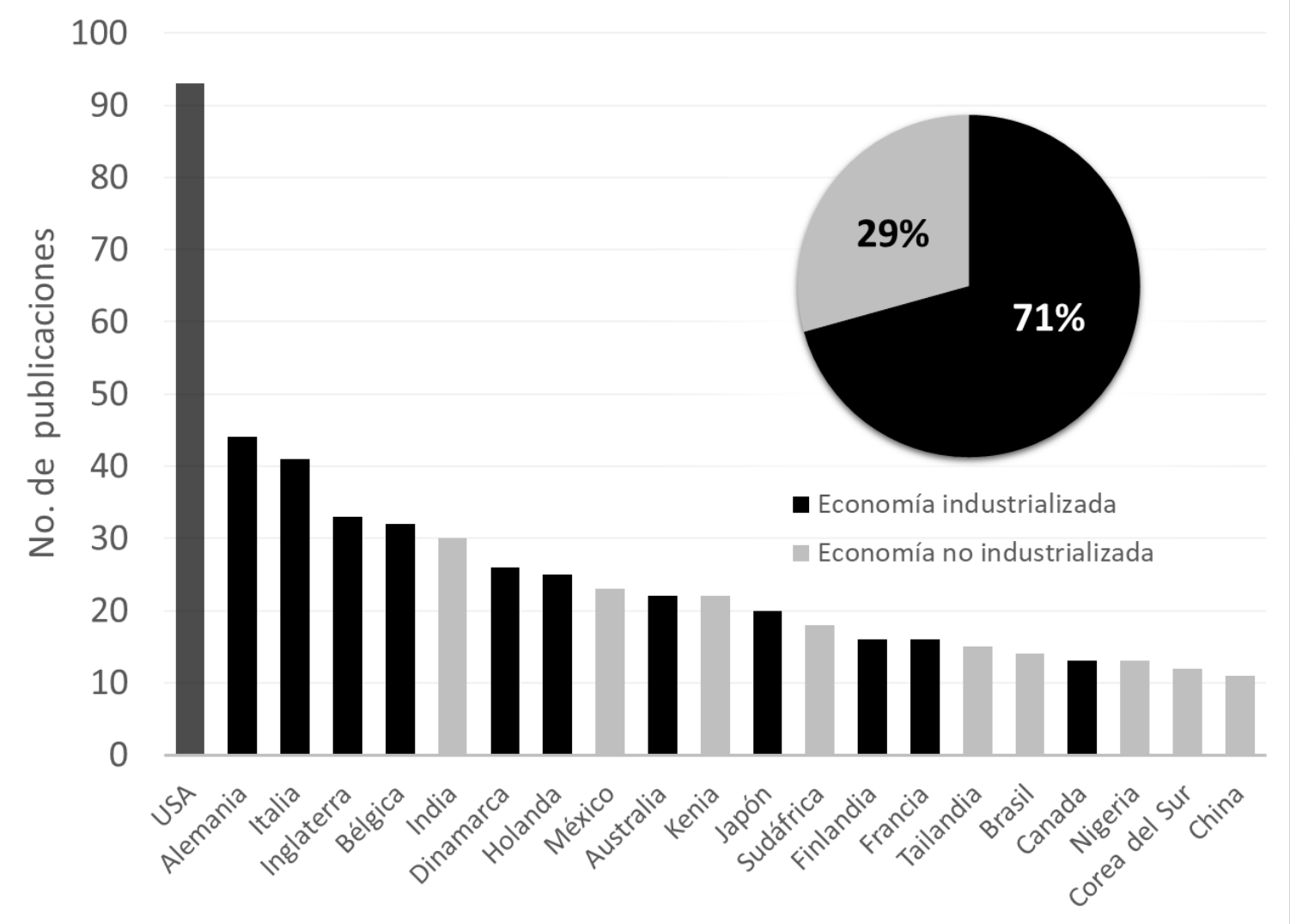

Figura 5. Productividad científica por país sobre insectos comestibles entre 1995 y 2020 (octubre). La mayor parte del nuevo conocimiento tecnocientífico sobre insectos comestibles proviene de países industrializados en donde (a excepción de Japón) la entomofagia no es considerada una práctica de alimentación convencional. Fuente: Web of Science. 

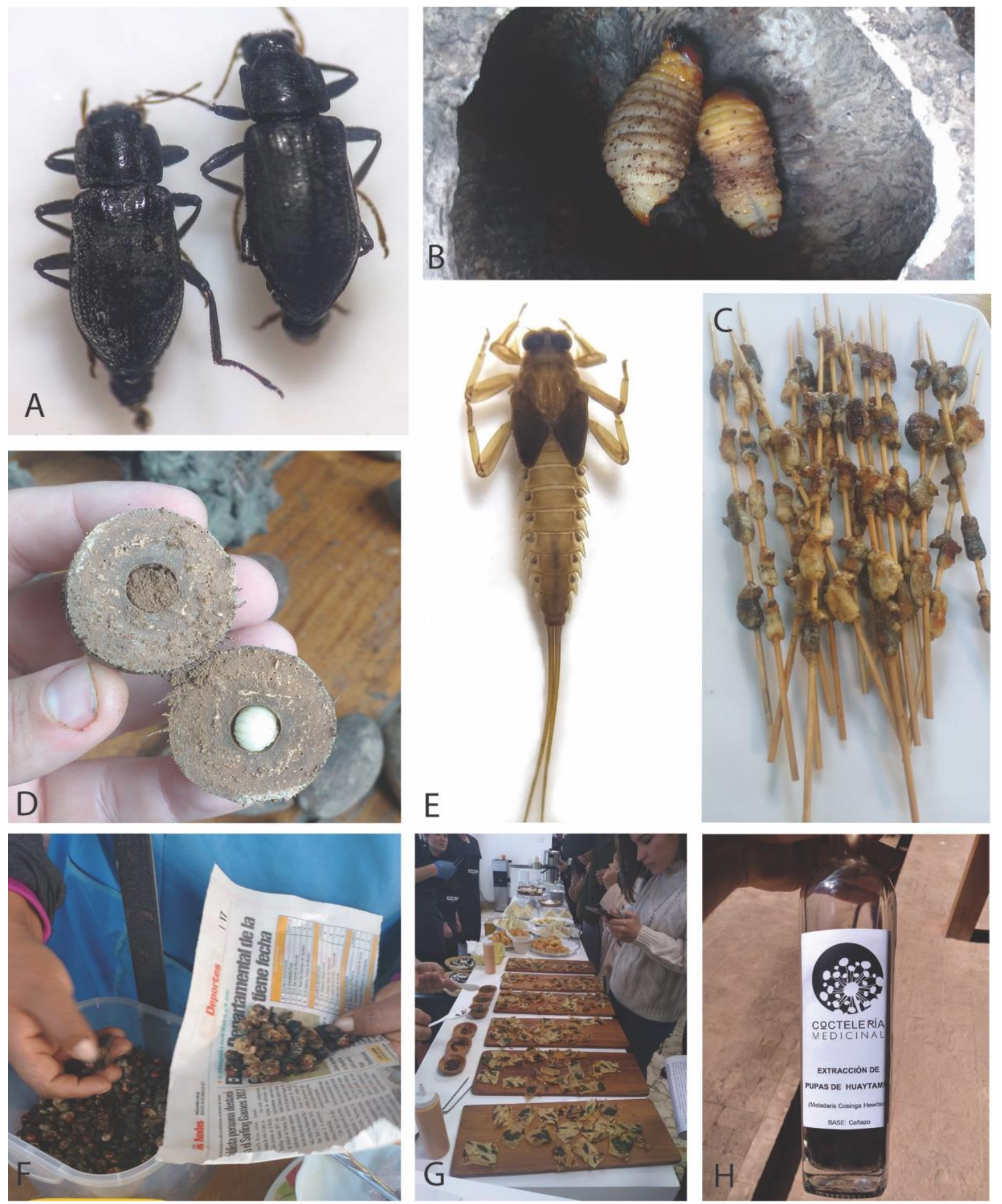

Figura 6. Miscelánea de insectos comestibles del Perú. A., Austrelmis condimentarius es un escarabajo acuático utilizado en la preparación del 'chupe de chichis' en algunas regiones andinas (Austrelmis sp. en la foto); B. Larvas de Rhynchophorus palmarum ("suri"), insecto comestible de bandera y cuyo consumo es difundido en el Perú amazónico; C. Larvas de suri a la parrilla para agasajar turistas en Tambobata, Madre de Dios; D. Fruto de Attalea phalerata ("shapaja") conteniendo una larva de Pachymerus nucleorum, una especie de interés por su delicado sabor, textura y potencial culinario; E. Lachlania sp., una efímera de hábitos acuáticos consumidos en Cusco y Puno (y posiblemente también en Arequipa, de donde proviene el ejemplar fotografiado), y en donde se les conoce genéricamente como "chichis"; F. Larvas de una especie no identificada de escarabajo (Scarabaeidae) comercializadas por los herbolarios del mercado Laykakota, Puno. G. Degustación de bocadillos gourmet a base de larvas del escarabajo Tenebrio molitor en evento público en Lima (creaciones de Ccori-Reciclaje Culinario); H. Experimentación con macerados de pupas de Metardaris cosinga ("Huaytampo"), Restaurante Mil, Cusco. 
Sin embargo, hay vacíos legales que limitan el uso de insectos para consumo humano, especialmente en países que carecen de un historial de consumo de insectos como los de la Unión Europea (LähteenmäkiUutela \& Grmelová, 2016). En claro contraste, en muchos países orientales donde la entomofagia está normalizada, dicha práctica no enfrenta mayores barreras legales que regulen el uso de insectos en la alimentación humana o animal - una gran ventaja en comparación a países occidentales. Sin embargo, aunque exista una gran predisposición por parte de empresas y gobiernos por desarrollar esta industria, los insectos por lo general suelen asociarse a condiciones insalubres y enfermedades, por lo que la percepción que las personas tienen hacia estos organismos suele ser una negativa (Kellert, 1993), esto a pesar de que solo es una fracción minúscula de especies, de entre las millones que existen, las que causan algún daño a los seres humanos. Por este motivo, existen barreras cognitivas y culturales importantes que deben ser superadas para que el mercado de los insectos comestibles en países occidentales experimente el desarrollo deseado (DeFoliart, 1999; Looy et al., 2014). En respuesta a esta problemática, un buen número de estudios enfocados en la actitud de los consumidores occidentales hacia la idea de comer insectos (o animales alimentados con estos, como peces o pollos) han emergido en años recientes. Estos buscan obtener información para, entre otros objetivos, desarrollar estrategias de marketing efectivas o identificar formas de comercialización más aceptables que fomenten el consumo y la formación de mercados (e.g. House, 2018). Del mismo modo, han surgido organismos como la Plataforma Internacional de Insectos para Alimento Humano y Animal (International Platform of Insects for Food and Feed, o IPIFF por sus siglas en inglés - ipiff.org), consorcio que representa los intereses de los actores involucrados en el sector de producción de insectos de la Unión Europea para de este modo impulsar su desarrollo.

\section{Rutas viables para el desarrollo de la entomofagia en el Perú}

Por su prevalencia en la Amazonía y en los Andes, los que constituyen un $88 \%$ del territorio, podemos afirmar que la entomofagia es una tradición cultural bien establecida en el Perú. Esto constituye un punto de partida importante para la implementación de políticas públicas orientadas a regular y promover la utilización de los insectos - y sus derivados — en el contexto de la seguridad alimentaria y sostenibilidad del medio ambiente. La normalización del uso de insectos como insumo alimentario para consumo humano seguramente requerirá de tiempo. Sin embargo, consideramos que existen rubros concretos que pueden desarrollarse en el corto y mediano plazo.

La actitud de los consumidores hacia los productos a base de insectos es un elemento clave para el éxito de la industria entomofágica en sociedades donde esta práctica no tiene arraigo tradicional. En el Perú este ámbito incluye principalmente los ambientes urbanos, especialmente los de la costa — donde se concentra la mayor población del Perú. Estudios muestran que las personas tienen una mejor disposición a intentar comer insectos en base a sus atributos sensoriales y visuales, así como también si cuentan con información confiable sobre su origen y seguridad (Mishyna et al., 2020). En ese sentido, la gastronomía peruana, una de las más reconocidas del mundo (Gálvez et al., 2017), representa una plataforma única para impulsar la entomofagia a través de la difusión y la innovación culinaria. De hecho, los insectos ya son objeto de exploración gastronómica en varias regiones del mundo y son en general considerados como ingredientes prometedores dentro del ámbito de la alta cocina (Lilholt, 2015; Halloran \& Flore, 2018). La integración de insectos a otros elementos y prácticas de la culinaria "mainstream" para enaltecer sus propiedades sensoriales, así como también para "rescatar" tradiciones culinarias que incorporen a estos como parte de una preparación, representan rutas viables para promover la aceptación progresiva de estos organismos como alimento en aquellos contextos socioculturales donde su consumo no está normalizado (Sogari et al., 2018; Mishyna et al., 2020). Énfasis en los beneficios a la salud y al medio ambiente que resultan de la entomofagia también ayudan a generar actitudes positivas en individuos neófitos, especialmente en los más jóvenes y con ideales personales compatibles (Menozzi et al., 2018; Sogari et al., 2019). Aunque existen instancias de experimentación gastronómica con insectos propiamente documentada en el Perú (Ocampo et $a l ., 2019)$, este es un ámbito que permanece virtualmente inexplorado y un nicho prometedor abierto a la creatividad e innovación. La gastronomía, en general considerada una herramienta poderosa para el cambio 
social (Navarro-Dols \& González-Pernía, 2020), puede constituirse una ruta clave para impulsar la normalización del consumo de insectos como alimento en el Perú .

La entomofagia podría también constituirse como una estrategia viable para suplir la dieta de poblaciones vulnerables, así como también para la promoción de industrias locales que fomenten el desarrollo de comunidades empobrecidas. Por ejemplo, solo en la región Andina, la cual alberga aproximadamente el 30 $\%$ de los peruanos, la anemia tiene una alta tasa de ocurrencia (Amerson et al., 2017) y afecta en promedio al $54.2 \%$ en la población infantil menor de 3 años (INEI, 2018). Esta problemática se atribuye a diversos factores históricos, entre ellos el uso ineficiente de los recursos naturales y cambios en el uso del suelo, provocando que cultivos andinos tradicionales de alto valor nutricional, como la quinua, sean desplazados por productos industrializados "modernos" pero nutricionalmente inferiores como el arroz y los fideos (Smith \& Trivelli, 2001). Los insectos son ricos en nutrientes y la mayoría de aquellos que son comestibles tienen un contenido de hierro similar o superior al de la carne de res (Bukkens, 2005; Mwangi et al., 2018). Por ello, los insectos comestibles constituyen un recurso estratégico para la prevención de enfermedades asociadas a la deficiencia de hierro en poblaciones de escasos recursos, tales como la anemia y el retraso del crecimiento (Christensen et al., 2006; Bauserman et. al., 2015; Mwangi et al., 2018). Por otro lado, la meliponicultura muestra un gran potencial para el desarrollo de negocios sostenibles centrados en la producción de miel de abejas meliponas. La meliponicultura supone además una serie de beneficios ambientales conexos, tales como la conservación de los hábitats naturales donde habitan las meliponas, desarrollo de la horticultura, promoción de emprendimientos familiares y/o comunitarios, agroturismo, entre otros (Mustafa et al., 2018). La miel de meliponas tiene un alto valor comercial y es considerada superior a la de Apis mellifera, la abeja común Europea. La meliponicultura es una industria que ha mostrado ser rentable en países que la han impulsado de manera estratégica, notablemente Malasia (Ismail \& Ismail, 2018). Esta práctica tiene un desarrollo incipiente en el Perú y por lo tanto urgen esfuerzos para mejorar las prácticas de manejo y tecnificación que ayuden a impulsar el desarrollo de esta industria.

Los insectos también muestran como una alternativa viable para suplir a las industrias que producen alimento para animales domésticos. Por ejemplo, el Perú es primer consumidor de pollo en Latinoamérica, con una demanda anual creciente que ya supera los $50 \mathrm{Kg} /$ per cápita según datos del Ministerio de Agricultura (MINAGRI), mientras que el sector acuícola, considerado un sector clave para la seguridad alimentaria, ha venido creciendo sostenidamente desde la década de 1990 (Berger, 2020), recibiendo además importante impulso desde el Gobierno peruano. Estudios experimentales enfocados en evaluar el rendimiento de crecimiento y propiedades sensoriales de los productos derivados de ambas industrias (i.e., pollos y peces), y alimentados parcial o totalmente con insectos, han mostrado resultados prometedores, lo cual ha derivado en un creciente interés por parte de estas industrias por incorporar a estos organismos en sus formulaciones de alimento (piensos) (e.g. Gasco et al., 2019; Dörper et al., 2020; Hua, 2020; revisado en Gasco et al., 2020). Es importante destacar que estas industrias son altamente dependientes de harina de pescado y frijol de soya, ambos recursos que verán su disponibilidad reducida por causa de los efectos que el calentamiento global tendrá en las condiciones físicas oceánicas y climáticas continentales, elevando además su costo de producción (Brander, 2007; Zhao et al., 2017). Este escenario demandará que los sectores avícola y acuícola peruanos apuesten por alternativas innovativas para la elaboración de pienso y que, al mismo tiempo, sean económicamente viables y ambientalmente sostenibles. Esta demanda requerirá emular y adaptar operaciones de producción masiva de insectos en granjas especialmente acondicionadas como las que ya existen en otras partes del mundo. La producción de piensos incorporando insectos y destinados a suplir a las industrias avícola y piscícola se muestra como una de las rutas más prometedoras para el uso industrial de estos organismos, en el corto y mediano plazo.

\section{CONCLUSIONES}

La entomofagia es una tradición cultural de largo arraigo en el Perú (Figura 6). El potencial que tienen los insectos para contribuir a la seguridad alimentaria de nuestra especie durante las próximas décadas parece 
estar bien establecido, al menos en teoría. Para que los insectos alcancen efectivamente dicho estatus, el desarrollo y promoción de la entomofagia es clave y debe darse desde múltiples frentes. Por un lado, están los impulsores del sector industrial y civil y, por el otro, las entidades gubernamentales encargadas de regular la producción, consumo seguro y la defensa de los derechos de los consumidores (Belluco et al., 2017; Usman \& Yusuf, 2020). Desde el punto de vista peruano, la entomofagia no deja de ser interesante porque a pesar de que es una tradición bien establecida en buena parte del territorio y por ello culturalmente diversa, los insectos no son usados como ingredientes en ninguna preparación o tradición gastronómica urbana "mainstream", estando su uso más bien restringido a prácticas culinarias rurales y localizadas (e.g. Manno et al., 2018). El uso de insectos como alimento no está regulado y mucho menos contemplado por ninguna legislación peruana, y tampoco son considerados explícitamente dentro de la Estrategia Nacional para la Seguridad Alimentaria 2013-2021 (MINAGRI, 2012). A pesar de ello, las normativas sobre seguridad alimentaria establecen el rol del Estado peruano en velar por el derecho a una alimentación adecuada a través de múltiples estrategias, siendo una de ellas la promoción de una cultura alimentaria y nutricional que rescate los conocimientos locales y prácticas tradicionales de alimentación. Este contexto jurídico aparentemente favorable, sumado a la rica plataforma gastronómica del Perú, y la importante diversidad de especies de insectos de facto comestibles que existen en el territorio, constituyen una oportunidad única para promover el aprovechamiento de este recurso como alimento humano y animal.

La brecha de conocimiento sobre insectos comestibles en el Perú es amplia y por lo tanto es urgente canalizar esfuerzos de investigación para indagar en las múltiples dimensiones que le son inherentes a la entomofagia. Por ejemplo, en la Amazonía peruana convergen un sinnúmero de saberes ancestrales sobre el consumo de insectos, en virtud de la gran diversidad de grupos indígenas que allí habitan y usan los recursos del bosque. Por ello, es prioritario conducir estudios de campo que busquen documentar las especies tradicionalmente consumidas por comunidades originarias y rurales, así como también las prácticas culturales y culinarias asociadas a dicho consumo. A esto se deben sumar esfuerzos orientados a indagar en la composición química de las especies de interés, así como también en sus propiedades organolépticas y funcionales. También es necesario generar información sobre el ciclo biológico de especies de interés para el desarrollo de protocolos de crianza y optimización de dietas en base a diferentes tipos de sustratos, dando preferencia a aquellos que viabilicen ciclos económicos circulares. Para establecer el impacto económico de la introducción de insectos en la alimentación animal, será necesario además realizar estudios de costobeneficio para indagar en mayor detalle cómo estos influyen efectivamente en los costos de producción. Finalmente, es fundamental impulsar el registro taxonómico y distribucional actualizado de las especies de insectos comestibles del Perú para así facilitar su uso estratégico y racional a nivel nacional y regional. En general, el Perú tiene un gran potencial para el desarrollo de una industria entomofágica innovadora y creativa que no solo podría contribuir con el desarrollo económico del país, sino también demostrará ser de gran valor como estrategia adaptativa ante los retos de transformación climática que se anticipan para el siglo XXI.

\section{AGRADECIMIENTOS}

Los autores expresan su agradecimiento a Clorinda Vergara Cobián (Museo de Entomología Klaus Raven Büller, Universidad Nacional Agraria La Molina, Lima), por facilitar acceso a la colección de insectos bajo su cuidado. Carlos Molina Vital (Center for Latin American and Caribbean Studies, University of Illinois, Urbana-Champaign, USA), quien tuvo la gentileza de asistirnos en el análisis del significado quechua de "chíchi". Ivan Best Cuba (Universidad San Ignacio de Loyola, Facultad de Ingeniería, Lima), quien proporcionó información relevante sobre aspectos técnicos relacionados a la composición química de los alimentos. Extendemos además nuestro agradecimiento al Centro Amazónico Antropológico de Aplicación Práctica de la Amazonia Peruana (CAAAP), Asociación Interétnica para el Desarrollo de la Selva Peruana (AIDESEP) y Fundación Peruana para la Conservación de la Naturaleza (PRONATURALEZA) por el apoyo logístico brindado a FC durante sus estudios de campo, así como también a todos los miembros de las diferentes comunidades visitadas, en especial a la Comunidad Indígena Matsigenka de Shipetiari. 
Finalmente, un agradecimiento especial a Eduardo Oyague Passuni (herbario Takana, Departamento de Biología, Universidad Nacional Jorge Basadre Grohmann, Tacna), por su asistencia y confianza, así como también a Gabriel Trujillo (Centro de Ornitologia y Biodiversidad (CORBIDI) por proporcionar fotografías de Lachlania sp. y Austrelmis sp.

\section{REFERENCIAS}

Aguilar, P. G., \& Sáenz, D. (1970). Algunas variaciones morfológicas en el grillo común de la costa central. Revista Peruana de Entomología, 13(1), 76-86.

Aguilera, D. S., Sánchez, L. D. R. F., Gil, M. D. J. A., Guevara, D. P. S., \& Poma, J. P. P. (2017). Los saberes ancestrales en el desarrollo local. Las larvas de Rhynchophorus palmarum L. como recurso alimentario de los pueblos amazónicos. Revista Amazónica Ciencia y Tecnología, 6(1), 35-44.

Alves, A. V., Sanjinez Argandona, E. J., Linzmeier, A. M., Cardoso, C. A. L., \& Macedo, M. L. R. (2016). Chemical composition and food potential of Pachymerus nucleorum larvae parasitizing Acrocomia aculeata kernels. PloS one, 11(3), e 0152125.

Amerson, R., Miller, L., Glatt, M., \& Baker, J. (2017). Assessment of anemia levels in infants and children in high altitude Peru. Global Journal of Health Science, 9(7), 87-95.

Apolo-Arévalo, L. A. \& Iannacone, J. (2015) Crianza del grillo (Acheta domesticus) como fuente alternativa de proteínas para el consumo humano. Scientia, 17(1): 155-167.

Baumgartner, D. L. \& Roubik, D. W. (1989). Ecology of Necrophilous and Filth-Gathering Stingless Bees (Apidae: Meliponinae) of Peru. Journal of the Kansas Entomological Society, 62(1), 11-22.

Bauserman, M., Lokangaka, A., \& Gado, J. (2015) A cluster-randomized trial determining the efficacy of caterpillar cereal as a locally available and sustainable complementary food to prevent stunting and anaemia. Public Health Nutrition, 18: 1785-1792

Belluco, S., Halloran, A., \& Ricci, A. (2017). New protein sources and food legislation: the case of edible insects and EU law. Food Security, 9(4), 803-814.

Berger, C. (2020). La acuicultura y sus oportunidades para lograr el desarrollo sostenible en el Perú. South Sustainability, 1(1): e003.https://doi.org/10.21142/SS-0101-2020-003

Blanco, V. , Chavarro, C., Polanco, Y. \& Ruiz, X. (2020). Insectos: Recursos del pasado que podrían ser una solución nutricional para el futuro. Avances en Investigacion Agropecuaria, 24(2), 81-100.

Blas, E. M. \& del Hoyo, J. (2013). Entomología cultural y conservación de la biodiversidad: los insectos en las Artes Mayores. Cuadernos de Biodiversidad, 42: 1-22.

Bodenheimer, F. S. (1951). Insects as Human Food: A Chapter of the Ecology of Man. Junk W. Dr, Publishers, the Hague. 352 pp.

Bonavia, D., Johnson, L. W., Reitz, E. J. Wing, E. S., \& Weir, G. H. (1993). Un sitio precerámico de Huarmey (PV35-6) antes de la introducción del maíz. Bulletin de l'Institut Français d'Etudes Andines, 22(2), 409-442.

Brander, K. M. (2007). Global fish production and climate change. Proceedings of the National Academy of Sciences, 104(50), 19709-19714.

Bukkens, G. F. (2005). Insects in the human diet: nutritional aspects. In: Paoletti M.G. (ed) Ecological implications of minilivestock: potential of insects, rodents, frogs and snails. Taylor \& Francis, Oxford.

Camargo, J. M. F. \& Pedro, S. R. M. (2013). Meliponini Lepeletier, 1836. In: Moure, J. S., Urban, D. \& Melo, G. A. R. (eds). Catalogue of Bees (Hymenoptera, Apoidea) in the Neotropical Region - online version. Disponible en: http://www.moure.cria.org.br/catalogue. Accessed Oct/09/2020.

Carbonell, C. S. (1986). Revision of the Neotropical genus Tropidacris (Orthoptera, Acridoidea, Romaleidae, Romaleinae). Proceedings of the Academy of Natural Sciences of Philadelphia, 138(2), 366-402. 
Cartay, R. (2018). Entre el asombro y el asco: el consumo de insectos en la cuenca amazónica. El caso del Rhynchophorus palmarum (Coleoptera Curculionidae). Revista Colombiana de Antropología, 54(2), 143-169.

Casas Reátegui, R., Pawera, L., Villegas Panduro, P.P. et al. (2018). Beetles, ants, wasps, or flies? An ethnobiological study of edible insects among the Awajún Amerindians in Amazonas, Peru. Journal of Ethnobiology and Ethnomedicine 14, 53. https://doi.org/10.1186/s13002-018-0252-5.

Catacora Y., F. \& Romero O, R. (2019). "Chhichi Kuru” en la etnomedicina Andina. Revista Cientifica Investigación Andina, 18(2): 13-23.

Cerda, H., Martínez, R., Briceño, N., Pizzoferrato, L., Manzi, P., Ponzetta, M. T., ... \& Paoletti, M. G. (2001). Palm worm: (Rhynchophorus palmarum) traditional food in Amazonas, Venezuela nutritional composition, small scale production and tourist palatability. Ecology of food and nutrition, 40(1), 13-32.

Chaboo, C. \& Morse, G. (2015). Beetles (Coleoptera) of Peru: A survey of the families. Chrysomelidae: Bruchinae Latreille, 1802. Journal of the Kansas Entomological Society, 88(3), 356-360.

Chaboo, C. S., \& Shepard, W. D. (2015). Beetles (Coleoptera) of Peru: A survey of the families. Dytiscidae, Gyrinidae, Haliplidae, and Noteridae (suborder Adephaga). Journal of the Kansas Entomological Society, 88(2), 146-150.

Christensen, D. L., Orech, F. O., Mungai, M. N., et al. (2006) Entomophagy among the Luo of Kenya: a potential mineral source? International Journal of Food Sciences and Nutrition, 57: 198-203..

Correa Tang, M. del R. \& Delgado, C. (2016). Los insectos desde la percepción de los estudiantes "Tikuna" y mestizos de educación básica del Municipio de Caballo Cocha. Ciencia Amazónica, 6(2), 109-115

Creão-Duarte, A. J., \& Sakakibara, A. M. (1996). Revisão do gênero Umbonia Burmeister (Homoptera, Membracidae, Membracinae, Hoplophorionini). Revista Brasileira de Zoologia, 13(4), 973-994.

Creed-Kanashiro, H., Roche, M., Cerron, I. T., \& Kuhnlein, H. V. (2009). Traditional food system of an Awajun community in Peru. Indigenous peoples' food systems: the many dimensions of culture, diversity and environment for nutrition and health, p. 59-81.

Creed-Kanashiro, H. M., Carrasco, M., Abad, M., \& Tuesta, I. (2013). Promotion of traditional foods to improve the nutrition and health of the Awajún of the Cenepa River in Peru. In: Kuhnlein HV, Erasmus B., Spigelski D., Burlingame B., editors. Indigenous peoples' food systems: the many dimensions of culture, diversity and environment for nutrition and health. Roma: FAO, p. 53-74.

Crespo, R., Villaverde, M. L., Girotti, J. R., Güerci, A., Juárez, M. P., \& de Bravo, M. G. (2011). Cytotoxic and genotoxic effects of defence secretion of Ulomoides dermestoides on A549 cells. Journal of Ethnopharmacology, 136(1), 204-209.

Cummins Jr, V. C., Rawles, S. D., Thompson, K. R., Velasquez, A., Kobayashi, Y., Hager, J., \& Webster, C. D. (2017). Evaluation of black soldier fly (Hermetia illucens) larvae meal as partial or total replacement of marine fish meal in practical diets for Pacific white shrimp (Litopenaeus vannamei). Aquaculture, 473, 337-344.

DeFoliart, G. R. (1999). Insects as food: why the western attitude is important. Annual review of Entomology, 44(1), 21-50.

Delgado, C., Couturier, G., Mathews, P., \& Mejia, K. (2008). Producción y comercialización de la larva de Rhynchophorus palmarum (Coleoptera: Dryophthoridae) en la Amazonía peruana. Boletín Sociedad Entomológica Aragonesa, 41, 407-412.

Delgado, C., Romero, R., Espinoza, R. V., Trigoso Pinedo, M., \& Correa Tang, M. D. R. (2019). Rhynchophorus palmarum used in traditional medicine in the Peruvian Amazon. Ethnobiology letters, 10(1), 120-128.

Denevan, W. M. (1971). Campa subsistence in the Gran Pajonal, Eastern Peru. Geographic Review, 61, 496518. 
Devic, E., Leschen, W., Murray, F., \& Little, D. C. (2018). Growth performance, feed utilization and body composition of advanced nursing Nile tilapia (Oreochromis niloticus) fed diets containing Black Soldier Fly (Hermetia illucens) larvae meal. Aquaculture nutrition, 24(1), 416-423.

Duarte, J. \& Mercado, C. (2001). Perfil técnico promocional de la sericultura y elaboración de hilo de seda en forma artesanal en la Selva Central de Perú: crianza del gusano de seda. Revista del INIAA-Sector Agrario, 2(4), 18-20.

Dörper, A., Veldkamp, T., \& Dicke, M. (2020). Use of black soldier fly and house fly in feed to promote sustainable poultry production. Journal of Insects as Food and Feed, 1-20.

Ericksen, P. J., Ingram, J. S., \& Liverman, D. M. (2009). Food security and global environmental change: emerging challenges. Environmental Science and Policy, 4 (12), 373-377.

Escomel, E. (1919). El Pseudomleoe espostoi. Anales de la Facultad de Medicina de Lima, 4, 159-163.

Escomel, E. (1926). Un nouveau pseudo-méloïde, insect medicinal du Pérou. Bulletins de la Société de pathologie exotique et de sa filial del'Ouest-Africain, 19, 198-201.

Escomel, E. \& Maldonado, A. (1921). Demostración que los insectos del género Pseudomeloe los emplearon en el antiguo Perú. Anales de la Facultad de Medicina de Lima, 7(3), 170-174.

Gasco, L., Biancarosa, I., \& Liland, N. S. (2020). From waste to feed: a review of recent knowledge on insects as producers of protein and fat for animal feeds. Current Opinion in Green and Sustainable Chemistry, 23. https://doi.org/10.1016/j.cogsc.2020.03.003

Gasco, L., Biasato, I., Dabbou, S., Schiavone, A., \& Gai, F. (2019). Animals fed insect-based diets: State-ofthe-art on digestibility, performance and product quality. Animals, 9(4), 170.

Elizalde, V, R, Castillo C, P.S. \& Rasmussen, C. (2007). Manual de abejas nativas sin aguijón de la Reserva de Biosfera del Nordeste del Perú (2da ed.). Tumbes: Universidad Nacional de Tumbes.

von Ellenrieder, N. (2003). A synopsis of the Neotropical species of "Aeshna" Fabricius: the genus Rhionaeschna Förster (Odonata: Aeshnidae). Tijdschrift voor Entomologie, 146(1), 67-207.

Erizalde V. R. \& Castillo-Carrillo, P. S. (2010). Identificación, morfología y comportamiento de la “abeja de tierra" Geotrigona fumipennis

Fernández Baca, G. (1980). La pintura Inka en cerámica. Serie Obras Maestras del Arte en el Antiguo Perú, Fascículo 1. Lima: Instituto Nacional de Cultura.

Gahukar, R. T. (2011). Entomophagy and human food security. International Journal of Tropical Insect Science, 31(3), 129-144.

Gálvez, J. C. P., López-Guzmán, T., Buiza, F. C., \& Medina-Viruel, M. J. (2017). Gastronomy as an element of attraction in a tourist destination: the case of Lima, Peru. Journal of Ethnic Foods, 4(4), 254-261.

Glover, D. and Sexton, A. (2015). Edible Insects and the Future of Food: A Foresight Scenario Exercise on Entomophagy and Global Food Security, IDS Evidence Report 149, Brighton: IDS.

Grados, J. (2002). Los Arctiidae y Sphingidae (Lepidoptera: Heterocera) del santuario histórico de Machu Picchu, Cuzco, Perú: estudio preliminar. Revista peruana de Biología, 9(1), 16-22.

Grados, J., Peralta, J., \& Venero, J. L. (2015). Los chíchis, insectos acuáticos (Ephemeroptera: Oligoneuriidae: Lachlania) en la alimentación del Imperio Incaico, Perú. Revista peruana de entomología, 50(2), 45-52.

Grimaldi, D., Engel, M. S., \& Engel, M. S. (2005). Evolution of the Insects. Cambridge University Press.

Halloran, A., \& Flore, R. (2018). A New World of Ingredients: Aspiring Chefs' Opinions on Insects in Gastronomy. In: Edible Insects in Sustainable Food Systems, Springer, Cham., p. 129-137.

Hazarika, A. K., Kalita, U., Khanna S., Kalita T., \& Choudhury, S. (2020). Diversity of edible insects in a Natural World Heritage Site of India: entomophagy attitudes and implications for food security in the region. PeerJ, 8, e10248 https://doi.org/10.7717/peerj.10248. 
Hogue, C. L. (1987). Cultural entomology. Annual Review of Entomology, 32(1), 181-199. doi:10.1146/annurev.en.32.010187.001145.

House, J. (2018). Insects as food in the Netherlands: Production networks and the geographies of edibility. Geoforum, 94, 82-93.

Huanachin, A. \& Huamantinco, A. (2018). Composición y estructura de la comunidad de coleópteros acuáticos (Insecta: Coleoptera) a lo largo de un gradiente altitudinal, Cusco, Perú. Revista Peruana de Biología, 25(2), 131-140.

Hua, K. (2020). A meta-analysis of the effects of replacing fish meals with insect meals on growth performance of fish. Aquaculture, 530: DOI:10.1016/j.aquaculture.2020.735732.

Van Huis, A., Van Itterbeeck, J., Klunder, H., Mertens, E., Halloran, A., Muir, G., \& Vantomme, P. (2013). Edible insects: future prospects for food and feed security (No. 171). Food and Agriculture Organization of the United Nations.

Iide, P. \& Mileti, D.I.C. (1976). Estudos Morfológicos sobre Hermetia illucens (Linnaeus, 1758) (Diptera, Stratiomyidae). Revista Brasileira de Biologia, 36 (4): 923-935.

INEI (2018). Indicadores de Resultados de los Programas Presupuestales, primer Semestre 2018: Encuesta Demográfica y de Salud Familiar. Lima: Instituto Nacional de Estadística e Informática.

Ismail, M. \& Ismail, W. (2018). Development of stingless beekeeping projects in Malaysia. E3SWC, 52, 00028.

Jankielsohn, A. (2018). The Importance of Insects in Agricultural Ecosystems. Advances in Entomology, $6(02), 62$.

Jara, N. \& Franco, J. (1985). El huaytampo Metardaris cosinga Hewitson, 1874 (Lepidoptera: Hesperiidae), en la alimentación del hombre andino. Revista de Zoología (UNSAAC), 1(1): 94-101.

Jongema, Y. (2017). List of edible insects of the world. Wageningen University, Wageningen, The Netherlands.

Juárez-Noé, G., \& González-Coronado, U. (2018). Lista De Coleópteros (Insecta: Coleoptera) de la Región Piura, Perú. Folia Entomológica Mexicana (n. s.), 4(1), 1-27.

Kellert, S. (1993). Values and perceptions of invertebrates. Conservation Biology: The Journal of the Society for Conservation Biology, 7, 845-855.

Kim, T. K., Yong, H. I., Kim, Y. B., Kim, H. W., \& Choi, Y. S. (2019). Edible Insects as a Protein Source: A Review of Public Perception, Processing Technology, and Research Trends. Food science of animal resources, 39(4), 521-540. https://doi.org/10.5851/kosfa.2019.e53

Lähteenmäki-Uutela, A., \& Grmelová, N. (2016). European law on insects in food and feed. European Food andFeed Law Review, 11(1), 2-8.

Lamas, G. (1976). Notes on Peruvian butterflies (Lepidoptera). I. The genus Phoebis Hübner, 1819 (Pieridae), with the description of a new subspecies. Revista Peruana de Entomología, 18, 5-9.

Lamas, G. (1977). Notas sobre mariposas peruanas (Lepidoptera). III. Sobre una colección efectuada en el departamento de Tumbes. Revista Peruana de Entomología, 19, 8-12.

Lamas, M. (1980). Introducción a la Historia de la Entomología en el Perú - I. Inicios y periodo exploratorio pre-darwiniano. Revista Peruana de Entomología, 23(1), 17-37.

Lamas, G. (1984). Los Papilionoidea (Lepidoptera) de la Zona Reservada de Tambopata, Madre de Dios, Perú. I: Papilionidae, Pieridae y Nymphalidae (en parte). Revista Peruana de Entomología, 27: 5973.

Lamas, G. (1995) A critical review of J.Y. Miller's Checklist of the Neotropical Castniidae (Lepidoptera). Revista peruana de Entomología, 37(1): 73-87.

Lamas, G. (2004). Atlas of Neotropical Lepidoptera-checklist: Part 4A Hesperioidea -Papilionoidea. Gainesville, Scientific Publishers, XXXVI+439p. 
Lamas, G., Robbins, R. \& Harvey, D. (1991). A preliminary survey of the butterfly fauna of Pakitza, Parque Nacional del Manu, Peru, with an estimate of its species richness. Publicaciones del Museo de Historia Natural Universidad Nacional Mayor de San Marcos (Serie A), 40, 1-19.

Leather, S. R. (2015). Influential entomology: a short review of the scientific, societal, economic and educational services provided by entomology. Ecological entomology, 40, 36-44.

Lecoq, M., \& Pierozzi Jr, I. (1996). Chromatic polymorphism and geophagy: two outstanding characteristics of Rhammatocerus schistocercoides (Rehn, 1906) grasshoppers in Brazil [Orthoptera, Acrididae, Gomphocerinae]. Journal of Orthoptera Research, 5, 13-17.

Lilholt, A. (2015). Entomological Gastronomy. North Carolina: Lulu.com Yayınevi.

Looy, H., Dunkel, F. V., \& Wood, J. R. (2014). How then shall we eat? Insect-eating attitudes and sustainable foodways. Agriculture and human values, 31(1), 131-141.

Madau, F., Arru, B., Furesi, R., \& Pulina, P. (2020). Insect farming for feed and food production from a circular business model perspective. Sustainability, 12(13), 5418.

Makkar, H. P. S., Tran, G., Heuze, V., Ankers, P. (2014). State-of-the-art on use of insects as animal feed. Animal Feed Science and Technology, 197: 1-33.

Manno, N., Zelada Estraver, W., Medina Tafur, C., Leon Torres, C., Schwarzinger, C., List, M., Schoefberger, W., Mejìa Coico, F. R., Mostacero Leon, J., Battisti, A., \& Paoletti, M. G. (2018). Edible Insects and other Chitin-Bearing Foods in Ethnic Peru: Accessibility, Nutritional Acceptance, and Food-Security Implications. Journal of Ethnobiology, 38(3), 424-447.

Mathis, W., Zatwarnicki, T., \& Krivosheina, M. (1993). Studies of Gymnomyzinae (Diptera: Ephydridae), V:A revision of the shore-fly genus Mosillus Latreille. Smithsonian Contributions to Zoology(USA), no. 548.

Mekonnen, M. \& Hoekstra, A. (2012). A global assessment of the water footprint of farm animal products. Ecosystems, 15(3), 401-415.

Mlcek, J., Rop, O., Borkovcova, M., \& Bednarova, M. (2014). A comprehensive look at the possibilities of edible insects as food in Europe-a review. Polish Journal of Food and Nutrition Sciences, 64(3), 147-157.

Menozzi, D., Sogari, G., Veneziani, M., Simoni, E., \& Mora, C. (2017). Eating novel foods: An application of the Theory of Planned Behaviour to predict the consumption of an insect-based product. Food quality and preference, 59, 27-34.

Menzel, P. \& D'Alusio, F.D. (1998). Man eating bugs. Berkeley, CA, USA.

Métraux, A. (1963). Tribes of the middle and upper Amazon River. Pp. 687-712, In: Steward, J. (ed) Handbook of South American Indians. Vol. 3, Cooper Square Publishers, New York.

McGrew, W. C. (2001). The other faunivory: primate insectivory and early human diet. In Meat-Eating and Human Evolution, ed. CB Stanford, HT Bunn, pp. 160-78. Oxford, UK: Oxford Univ. Press. 384

MINAGRI. (2012). Estrategia Nacional Seguridad Alimentaria 2013-2021. Ministerio de Agricultura y Riego, Lima.

Mishyna, M., Chen, J., \& Benjamin, O. (2020). Sensory attributes of edible insects and insect-based foods Future outlooks for enhancing consumer appeal. Trends in Food Science \& Technology, 95, 141148.

Moure, J. S. (2012). Xylocopini Latreille, 1802. In Moure, J. S., Urban, D. \& Melo, G. A. R. (Orgs). Catalogue of Bees (Hymenoptera, Apoidea) in the Neotropical Region - online version. Available at http://www.moure.cria.org.br/catalogue. Accessed Oct/09/2020.

Mustafa, M. Z., Yaacob, N. S., \& Sulaiman, S. A. (2018). Reinventing the Honey Industry: Opportunities of the Stingless Bee. The Malaysian Journal of Medical Sciences, 25(4), 1-5.

Mwangi, M. N., Oonincx, D. G., Stouten, T., Veenenbos, M., Melse-Boonstra, A., Dicke, M., \& Van Loon, J. J. (2018). Insects as sources of iron and zinc in human nutrition. Nutrition research reviews, $31(2)$, 248-255. 
Natt, B. S., Campion, J. M., \& Knox, K. S. (2014). Acute eosinophilic pneumonia associated with ingestion of Ulomoides dermestoides larvae ("Chinese Beetles"). Annals of the American Thoracic Society, $11(10), 1667-1668$.

Navarro-Dols, J., \& González-Pernía, J. L. (2020). Gastronomy as a real agent of social change. International Journal of Gastronomy and Food Science, 21: DOI:10.1016/j.ijgfs.2020.100240.

Noé, G. \& Coronado, U. (2016a). Los Sphingidae Latreille, 1802 (Lepidoptera: Bombycoidea) de la Región Piura (Perú). Arquivos Entomolóxicos, 16, 61-66.

Noé, G. \& Coronado, U. (2016b). Los Sphingidae Latreille, 1802 (Lepidoptera: Bombycoidea) de la Región Tumbes (Perú). Arquivos Entomolóxicos, 16, 307-310.

Novoa, S. (2006). Sobre el Origen de la Tuna en el PerúAlgunos alcances. Zonas áridas, 10(1), 174-181.

Ocampo, P., Rojas, R., Amasifuen, C., Amasifuen, F., Sangam, A., Castro, A., Ruiz, A., Correa, A., \& Sauvain, M. (2019). Sabrosos Insectos Peruanos: Del Alimento Tradicional a la Innovación Gastronómica. Lima.

Oghenesuvwe, E. E., \& Paul, C. (2019). Edible insects bio-actives as anti-oxidants: Current status and perspectives. Journal of Complementary Medicine, 10(2), 89-102.

Ojha, S., Bußler, S., \& Schlüter, O. K. (2020). Food waste valorisation and circular economy concepts in insect production and processing. Waste Management, 118, 600-609.

Ollerton, J., Winfree, R., \& Tarrant, S. (2011). How many flowering plants are pollinated by animals? Oikos, 120(3), 321-326.

Onore, G. (1997). A brief note on edible insects in Ecuador. Ecology of Food and Nutrition, 36 (2-4), 277285.

Oonincx, D., Van Broekhoven, S., Van Huis, A., \& van Loon, J. J. (2015). Feed conversion, survival and development, and composition of four insect species on diets composed of food by-products. PloS one, 10(12): $\mathrm{e} 0144601$.

Paoletti, M., Buscardo, E., \& Dufour, D. (2000). Edible invertebrates among Amazonian Indians: a critical review of disappearing knowledge. Environment, Development and Sustainability, 2(3-4), 195-225.

Pastor, S., Fuentealba, B., \& Ruiz, M. (2006). Cultivos Subutilizados en el Perú: Análisis de las Políticas Públicas Relativas a su Conservación y Uso Sostenible. The Global Facilitation Unit for Underutilised Species (GFU).

Patel, S., Suleria, H. \& Rauf, A. (2019). Edible insects as innovative foods: Nutritional and functional assessments. Trends in Food Science \& Technology, 86, 352-359.

Paul, A., Frederich, M., Megido, R. C., Alabi, T., Malik, P., Uyttenbroeck, R., ... \& Danthine, S. (2017). Insect fatty acids: A comparison of lipids from three Orthopterans and Tenebrio molitor L. larvae. Journal of Asia-Pacific Entomology, 20(2), 337-340.

Payne, C. L., \& Van Itterbeeck, J. (2017). Ecosystem services from edible insects in agricultural systems: a review. Insects, 8(1), 24.

Pérez, D., \& Iannacone, J. (2006). Aspectos de la bioecología de Rhynchophorus palmarum (Linnaeus) (Coleoptera: Curculionidae) en el pijuayo (Bactris gasipaes HBK) (Arecaceae), en la Amazonia Peruana. Revista Peruana de Entomología, 45: 138-140.

Perichon, S. (2013). From Melipona beekeeping to modern beekeeping: an ethnozoological survey in tropical dry forests of Peru. Cahiers Agricultures, 22(2), 96-103.

Philippi, R.A. (1864). Ein Kaferchen, das als Gewurz dient. Stettiner Entomologische Zeitung, 25, 93-96.

Pieterse, E., Erasmus, S. W., Uushona, T., \& Hoffman, L. C. (2019). Black soldier fly (Hermetia illucens) pre-pupae meal as a dietary protein source for broiler production ensures a tasty chicken with standard meat quality for every pot. Journal of the Science of Food and Agriculture, 99(2), 893-903.

Racheli, L. (2006). List of the Arsenurinae of Peru with taxonomic notes on Titaea raveni (Johnson \& Michener, 1948) stat. rev. and Parademonia castanea (Rothschild, 1907) stat. rev. (Lepidoptera, Saturniidae). Galathea, 22(1), 41-47. 
Ramos-Elorduy, J. (2009). Anthropo-entomophagy: Cultures, evolution and sustainability. Entomological Research, 39(5), 271-288.

Rasmussen, C. (2003). Clave de identificación para las especies peruanas de Bombus Latreille, 1809 (Hymenoptera, Apidae), con notas sobre su biología y distribución. Revista Peruana de Entomología, 43, 31-45.

Rasmussen, C., \& Asenjo, A. (2009). A checklist to the wasps of Peru (Hymenoptera, Aculeata). Zookeys, $15,1-78$.

Ratcliffe, B. C., Jameson, M. L., Figueroa, L., Cave, R. D., Paulsen, M. J., Cano, E. B., . . Reyes-Castillo, P. (2015). Beetles (coleoptera) of Peru: A survey of the families. Scarabaeoidea. Journal of the Kansas Entomological Society, 88(2), 186-207.

Raubenheimer, D., \& Rothman, J. M. (2013). Nutritional ecology of entomophagy in humans and other primates. Annual Review of Entomology, 58, 141-160.

Roberts, H. R., \& Carbonell, C. S. (1981). A revision of the Neotropical genus Abracris and related genera (Orthoptera, Acrididae, Ommatolampinae). Proceedings of the Academy of Natural Sciences of Philadelphia, 133, 1-14.

Rodhain, F. (2015). Insects as vectors: systematics and biology. Revue scientifique et technique (International Office of Epizootics), 34(1), 83-96.

Rodríguez, L., U. Pascual \& H. Niemeyer. (2006). Local identification and valuation of ecosystem goods and services from Opuntia scrubland in Ayacucho, Peru. Ecological Economics, 57, 30-44.

Rodríguez-Malaver, A. J., Rasmussen, C., Gutiérrez, M. G., Gil, F., Nieves, B., \& Vit, P. (2009). Properties of Honey from Ten species of Peruvian Stingless Bees. Natural Product Communications, 4(9). https://doi.org/10.1177/1934578X0900400913.

Rasmussen, C. (2003). Brodløse Honningbier I Peru. Naturensverden, 9, 14-25.

Rasmussen, C., \& Castillo, P. (2003). Estudio preliminar de la Meliponicultura o apicultura silvestre en el Perú (Hymenoptera: Apidae, Meliponini). Revista Peruana de Entomología, 43, 159-164.

Rasmussen, C \& Delgado, C (2019) Abejas sin aguijón (Apidae: Meliponini) en Loreto, Perú. Iquitos: Instituto de Investigaciones de la Amazonía Peruana.

Rasmussen, C., \& González, V. H. (2009). Abejas sin aguijón del Cerro Escalera, San Martín, Perú (Hymenoptera: Apidae: Meliponini). Sistemas Agroecológicos y Modelos Biomatemáticos, 2, 2632.

Roche, M. L., Creed-Kanashiro, H. M., Tuesta, I., \& Kuhnlein, H. V. (2008). Traditional food diversity predicts dietary quality for the Awajun in the Peruvian Amazon. Public health nutrition, 11(5), 457465.

Roche, M. L., Creed-Kanashiro, H. M., Tuesta, I., \& Kuhnlein, H. V. (2007). Traditional food system provides dietary quality for the Awajún in the Peruvian Amazon. Ecology offood and nutrition, 46(56), 377-399.

Roche, M. L., Creed-Kanashiro, H. M., Tuesta, I., \& Kuhnlein, H. V. (2011). Infant and young child feeding in the Peruvian Amazon: the need to promote exclusive breastfeeding and nutrient-dense traditional complementary foods. Maternal \& Child Nutrition, 7(3), 284-294.

Rojas Zolezzi, E (2003) Las clasificaciones asháninca de la fauna del piedemonte central: un caso de diferentes niveles de aproximación. Bulletin de L'Institu Francaise d'Études Andines, 32(1), 185212.

Romero O., R. \& Catacora Y, F. (2017). Etnoentomología en la Cosmovisión Andina del Altiplano Peruano. Revista Cientifica Investigación Andina, 17(1), 73-79. 
Rumpold, B. A., \& Schlüter, O. K. (2013). Nutritional composition and safety aspects of edible insects. Molecular Nutrition \& Food Research, 57(5), 802-823.

Safenraiter, M. E., Campos-Soldini, M. P., Fernández E., E. N., \& del Rio, M. G. (2019). Escarabajos vesicantes Sudamericanos (Coleoptera: Meloidae). Aportes al estado del conocimiento del género andino Pseudomeloe Fairmaire y Germain. Idesia, 37(1), 101-113.

Sanborn, A. F. (2020). The cicadas (Hemiptera: Cicadidae) of Peru including the description of twenty-four new species, three new synonymies, and thirty-seven new records. Zootaxa, 4785(1), 1-129.

Sancho, D. (2012). Rhynchophorus palmarum (Coleoptera: Curculionidae) en la Amazonía, un insecto en la alimentación tradicional de las comunidades nativas. Revista Amazónica Ciencia y Tecnología, 1(1), 51-57.

Santos, R., Lunardelli, A., Caberlon, E., Alves, C. Bordignon, F..., Rodriguez, J. (2010). Antiinflammatory and Immunomodulatory Effects of Ulomoides dermestoides on Induced Pleurisy in Rats and Lymphoproliferation In Vitro. Inflammation, 3, 173-179.

Scheffrahn, R. H., Krecek, J., Szalanski, A. L., \& Austin, J. W. (2005). Synonymy of Neotropical arboreal termites Nasutitermes corniger and $N$. costalis (Isoptera: Termitidae: Nasutitermitinae), with evidence from morphology, genetics, and biogeography. Annals of the Entomological Society of America, 98(3), 273-281.

Scudder, G. (2009). The importance of insects. In: Insect biodiversity: Science and society, (Edited by Foottit R.J. \& P. H. Adler), p. 7-32.

Sogari, G., Menozzi, D., \& Mora, C. (2018). Sensory-liking expectations and perceptions of processed and unprocessed insect products. International Journal on Food System Dynamics, 9(4), 314-320.

Sogari, G., Menozzi, D., \& Mora, C. (2019). The food neophobia scale and young adults' intention to eat insect products. International Journal of Consumer Studies, 43(1), 68-76.

Smith, S. M. \& Trivelli C. (2001). El consumo urbano de alimentos andinos tradicionales en el Perú. Colección Mínima, No. 40, IEP/MSP/ PyMAGROS. Lima, 87 pp.

Smith, A. , Mendoza, A. E., Flores, G. E., \& Aalbu, R. L. (2015). Beetles (Coleoptera) of Peru: A survey of the families. Tenebrionidae. Journal of the Kansas Entomological Society, 88(2), 221-228.

Stadtlander, T., Stamer, A., Buser, A., Wohlfahrt, J., Leiber, F., \& Sandrock, C. (2017). Hermetia illucens meal as fish meal replacement for rainbow trout on farm. Journal of Insects as Food and Feed, 3(3), 165-175.

Steinfeld, H., Gerber, P., Wassenaar, T., Castel, V., Rosales, M., \& de Haaan, C. (2006). Livestock's Long Shadow: Environmental Issues and Options. Food and Agriculture Organization of the United Nations.

Steward, J. H \& Métraux, A. (1948). The Peban Tribes. In: Steward, J.H (ed) The Tropical Forest Tribes, 727-736. Washington 1946-1950: Washington: Smithsonian Institution, Washington: Bureau of American Ethnology.

Steward, J. \& Métraux, A. (1963). (originally published 1948). Tribes of the Peruvian and Ecuadorian Montana. In: Handbook of South American Indians, Vol. 3, Cooper Square Publishers, New York, pp. 535-656.

Stork, N. E. (1993). How many species are there? Biodiversity and Conservation 2: 215-232.

Stork, N. E., McBroom, J., Gely, C., \& Hamilton, A. J. (2015). New approaches narrow global species estimates for beetles, insects, and terrestrial arthropods. Proceedings of the National Academy of Sciences, 112(24), 7519-7523.

Stork, N. E. (2018). How many species of insects and other terrestrial arthropods are there on Earth? Annual Review of Entomology, 63, 31-45.

Steinmann, H. (2013). World Catalogue of Odonata II: Anisoptera. Walter de Gruyter.

Suclli, E., Moriano, M., \& Deza, J. (2019). La clase Insecta en la Iconografía Inka. Ciencia y Desarrollo, 22(3), 63-89. 
Tilman, D., \& Clark, M. (2014). Global diets link environmental sustainability and human health. Nature, 515(7528), 518-522.

Tilman D., Fargione, J., Wolff, B., D'Antonio, C., Dobson, A., Howarth, R., Schindler, D., Schlesinger, W. H., Simberloff, D., \& Swackhamer, D. (2001). Forecasting agriculturally driven global environmental change. Science 292, 281-284.

Tilman, D., Balzer, C., Hill, J., \& Befort, B. L. (2011). Global food demand and the sustainable intensification of agriculture. Proceedings of the National Academy of Sciences, 108(50), 2026020264.

Usman, H. S., \& Yusuf, A. A. (2020). Legislation and legal framework for sustainable edible insects use in Nigeria. International Journal of Tropical Insect Science, https://doi. org/10.1007/s42690-02000291-9

Valdez Pantoja, C. \& Untiveros Bermúdez, G. (2010). Extracción y caracterización del aceite de las larvas del Tenebrio molitor. Revista de la Sociedad Química del Perú, 76(4), 407-414.

Vargas, G. E., Espinoza, G., Ruiz, C., \& Rojas, R. (2013). Valor nutricional de la larva de Rhynchophorus palmarum L.: comida tradicional en la Amazonía peruana. Revista de la Sociedad Química del Perú, 79(1), 64-70.

Vargas-Musquipa, W. F. (1995). Insectos en la iconografía Inka. Revista Peruana de Entomología, 37, 2329.

Vaurie, P. (1966). A revision of the Neotropical genus Metamasius (Coleoptera, Curculionidae, Rhynchophorinae): Species groups I and II. Bulletin of the American Museum of Natural History, 131(3), 1-119.

Venero, J.L., Tupayachi, A \& Ochoa, J. G. (1987). Hospederos de Metardaris cosinga (Lep., Hesperiidae). Revista Peruana de Entomología, 28, 31-33.

Vera Cedeño, H. (2020). Caracterización de la composición nutricional de la harina del grillo común (Gryllus assimilis). Trabajo de titulación previo a la obtención del Título de Químico de Alimentos. Carrera de Química de Alimentos. Quito: UCE.

Wheeler, T., \& Von Braun, J. (2013). Climate change impacts on global food security. Science, 341(6145), 508-513.

Weir, G. \& Bonavia, D. (1985). Coprolitos y dieta del Precerámico Tardío de la costa peruana. Bulletin de l'Institut Français d'Etudes Andines, 14(1-2), 85-140.

Zelada, H. (2004). Las mariposas diurnas (Lepidóptera: Hesperioidae y Papilionoidae) del Bosque de Cuyas, Ayabaca, Piura, Perú. Revista Peruana de Entomología, 44, 37-41.

Zhao, C., Liu, B., Piao, S., Wang, X., Lobell, D. B., Huang, Y., ... \& Durand, J. L. (2017). Temperature increase reduces global yields of major crops in four independent estimates. Proceedings of the National Academy of Sciences, 114(35), 9326-9331.

Zielińska, E., Karaś, M., Jakubczyk, A., Zieliński, D., \& Baraniak, B. (2019). Edible insects as a source of proteins. Bioactive molecules in food, Reference series in phytochemistry. Cham, Springer Nature. 